\title{
From Euler, Ritz, and Galerkin to Modern Computing*
}

Martin J. Gander ${ }^{\dagger}$

Gerhard Wanner ${ }^{\dagger}$

\begin{abstract}
The so-called Ritz-Galerkin method is one of the most fundamental tools of modern computing. Its origins lie in Hilbert's "direct" approach to the variational calculus of EulerLagrange and in the thesis of Walther Ritz, who died 100 years ago at the age of 31 after a long battle with tuberculosis. The thesis was submitted in 1902 in Göttingen, during a period of dramatic developments in physics. Ritz tried to explain the phenomenon of Balmer series in spectroscopy using eigenvalue problems of partial differential equations on rectangular domains. While this physical model quickly turned out to be completely obsolete, his mathematics later enabled him to solve difficult problems in applied sciences. He thereby revolutionized the variational calculus and became one of the fathers of modern computational mathematics. We will see in this article that the path leading to modern computational methods and theory involved a long struggle over three centuries requiring the efforts of many great mathematicians.
\end{abstract}

Key words. Walther Ritz, variational calculus, finite element method

AMS subject classifications. AUTHOR: PLEASE PROVIDE

DOI. $10.1137 / 100804036$

I. The Variational Calculus of Euler and Lagrange. The most well-known contribution of Walther Ritz is the development of a systematic approach for solving variational problems. His methods transformed variational calculus from a theoretical tool to one of practical importance, and they are the precursor to many algorithms in modern scientific computing. Going back in history, we will see how variational calculus started in 1696 with the famous challenge concerning the brachystochrone problem, which led to endless disputes between the Bernoulli brothers. Euler [12] gave in 1744 a general solution to variational problems in the form of a differential equation. Eleven years later, the nineteen-year-old Lagrange then communicated, in a famous letter to Euler, an elegant justification for this equation. The prodigious contributions of Euler concerning the analytic and numerical solutions of differential equations, in particular, his Institutiones Calculi Integralis [13] from 1768-1770, then added the finishing touch to the theory.

I.I. The Brachystochrone Problem. In 1696, Johann Bernoulli challenged the mathematical world (which included his brother Jacob) with the following problem (see Figure 1.1): Given two fixed points $A$ and $B$ in a vertical plane, find a curve $A M B$ such that a body gliding on it under gravity, starting from $A$, arrives after the

\footnotetext{
${ }^{*}$ Received by the editors July 30, 2010; accepted for publication (in revised form) September 29, 2011; published electronically November 8, 2012.

http://www.siam.org/journals/sirev/54-4/80403.html

†Section de Mathématiques, Université de Genève, CP 64, 1211 Genève (Martin.Gander@ unige.ch, Gerhard.Wanner@unige.ch).
} 
shortest possible time at $B$, or, in beautiful Latin: Datis in plano verticali duobus punctis $A \& B$, assignare Mobili $M$ viam $A M B$, per quam gravitate sua descendens, 83 moveri incipiens a puncto A, brevissimo tempore perveniat ad alterum punctum $B$. Galileo, in 1638 , already knew that the shortest path, the straight line between $A$ and $B$, is not the quickest, and he guessed wrongly that a circle would be the best solution. The true shape of the best curve remained a mystery for nearly a century.
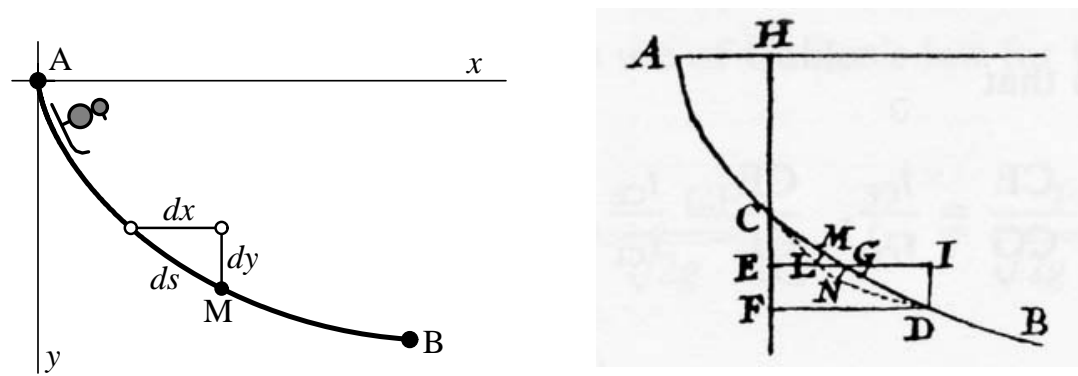

Fig. I.I The brachystochrone problem (left); Jacob Bernoulli's solution (right).

In order to turn this physical question into a mathematical one,${ }^{1}$ we notice that the time for covering a small arc length $d s$ is $d J=\frac{d s}{v}$. Inserting $v=\sqrt{2 g y}$ (Galileo), we obtain the problem of finding a function $y(x)$ with $y(a)=A, y(b)=B$ such that the integral

$$
J=\int_{a}^{b} \frac{\sqrt{d x^{2}+d y^{2}}}{\sqrt{2 g y}}=\int_{a}^{b} \frac{\sqrt{1+p^{2}}}{\sqrt{2 g y}} d x \longrightarrow \min , \quad \text { where } \quad p=\frac{d y}{d x} .
$$

We will see below that the optimal solution is a cycloide, which allowed Johann Bernoulli to proudly correct an error of Galileo.

I.2. Euler's Differential Equation for a Variational Problem. Half a century later appeared Euler's famous Methodus inveniendi lineas curvas [12] (E65, 1744), which solved a great variety of minimization problems, among them

$$
J=\int_{a}^{b} Z(x, y, p) d x \longrightarrow \min / \max , \quad \text { where } p=\frac{d y}{d x}
$$

where $Z$ is an arbitrary function; see Figure $1.2 .^{2}$

Euler's TheOREM. For an optimal solution, we have

$$
N-\frac{d}{d x} P=0, \quad \text { where } \quad N=\frac{\partial Z}{\partial y}, \quad P=\frac{\partial Z}{\partial p} .
$$

\footnotetext{
${ }^{1}$ Letter of de l'Hôpital to Johann Bernoulli, June 15th, 1696: "Ce probleme me paroist des plus curieux et des plus jolis que l'on ait encore proposé et je serois bien aise de m'y appliquer; mais pour cela il seroit necessaire que vous me l'envoyassiez reduit à la mathématique pure, car le phisique m'embarasse ...."

${ }^{2}$ To represent his mathematical colleagues as dogs barking at a theory (the brachystochrone), nailed out of their reach high up on a tree, was not Euler's style, but it was Johann Bernoulli's, who had produced the picture for his own Opera omnia in 1742. The editor, M. Bousquet, thought it a good idea to reuse the printing plate two years later. Perhaps Bousquet thought that Euler was an ape sitting still higher up in the tree and eating up all the coconuts.
} 


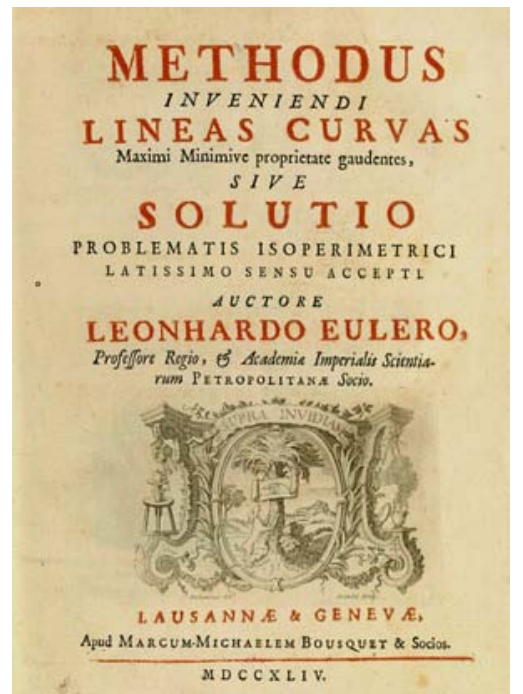

Variational Calc. 1744 E65

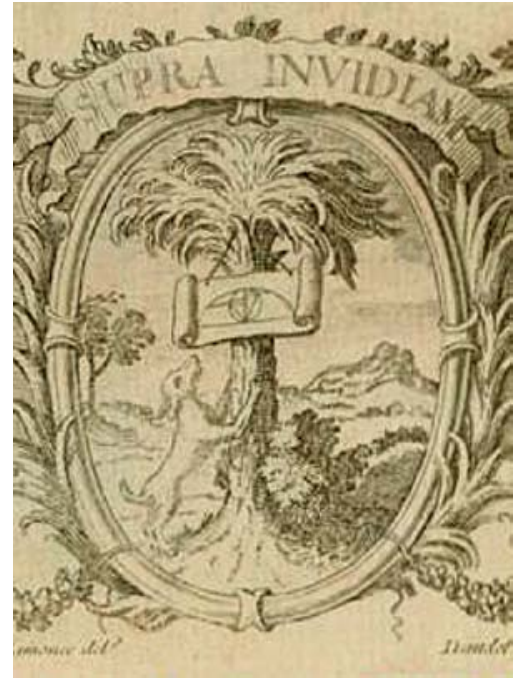

Zoom: above envy!

Fig. I.2 Euler's legacy for the theory of variational calculus, with a zoom.

We will come back later to Euler's proof of this formula. Because the term $P$ is in general a function of $p=y^{\prime}$, and because this term is differentiated once again in Euler's equation, we usually obtain a second order ordinary differential equation for $y(x)$, which may be difficult to solve. In the case where $Z$ is independent of $x$, i.e., if $d Z=N d y+P d p$, Euler found, in section 30 of Caput II of E65 [12], an elegant way to reduce the order: multiply

$$
N-\frac{d P}{d x}=0 \quad \text { by } \quad d y=p d x \quad \Rightarrow \quad N d y-p d P=0,
$$

then add and subtract $P d p$ to obtain

$$
\underbrace{N d y+P d p}_{d Z}-\underbrace{(p d P+P d p)}_{d(p \cdot P)}=0 \Rightarrow Z-p \cdot \frac{\partial Z}{\partial p}=\text { const. }
$$

Example 1 (smallest curve length, smallest energy; Euler E65 [12], Caput II, section 33). We search for a curve with $y(a)=A, y(b)=B$ of shortest arc length, i.e.,

$$
J=\int_{a}^{b} \sqrt{1+p^{2}} d x \longrightarrow \min .
$$

Here, $N=0$ and we obtain from (1.3) that $\frac{d P}{d x}=0$, i.e., $P=\frac{p}{\sqrt{1+p^{2}}}$ must be constant; thus $p=$ constant too. Not surprisingly, the solution is a straight line. Euler explains that the same result is valid for any problem where $Z$ depends uniquely on $p$. An interesting case is

$$
J=\int_{a}^{b} \frac{p^{2}}{2} d x \longrightarrow \min , \quad \text { for which }(1.3) \text { becomes } \quad-\frac{d^{2} y}{d x^{2}}=0 .
$$


This represents an approximation of $J$ in (1.5) for small $p$ and models a stretched flexible cord. If a transversal force $f(x)$ acts on the cord, we get the problem

$$
\begin{gathered}
J=\int_{a}^{b}\left(\frac{p^{2}}{2}-f \cdot y\right) d x \rightarrow \min , \\
\text { which leads to } \\
-\frac{d^{2} y}{d x^{2}}=f(x) .
\end{gathered}
$$

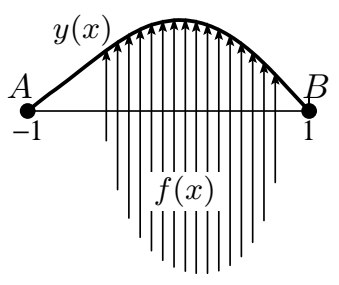

This case was too simple for Euler to mention, but its extension to higher dimensions will become very important later.

Example 2 (the brachystochrone problem; Euler E65 [12], Caput II, section 34). We obtain from (1.4)

$$
\frac{\sqrt{1+p^{2}}}{\sqrt{2 g y}}-\frac{p^{2}}{\sqrt{2 g y} \sqrt{1+p^{2}}}=C \quad \text { or } \quad 1=\sqrt{1+p^{2}} \sqrt{2 g y} \cdot C .
$$

It is still not a trivial matter to find a curve with this property. We remark that Johann Bernoulli, with one of his typically brilliant intuitions, arrived immediately at this last equation by applying Snell's law of light refraction. Because $\frac{\sin \alpha}{v}=$ const $=$ $\frac{1}{v} \frac{d x}{d s}=1 /\left(\sqrt{1+p^{2}} \sqrt{2 g y}\right)$, by (1.8) this law is satisfied everywhere and represents, by Fermat's principle, the quickest path.

I.3. Euler's Integral Calculus. A considerable part of Euler's tremendous work was devoted to analytical and numerical methods for the solution of integrals and differential equations. This work culminated in the three volumes of Institutiones Calculi Integralis [13] (E342, E366, E385, published 1768-1770). Let us apply these methods to find the solution of the brachystochrone problem (1.8): we solve the equation for $p=\frac{d y}{d x}$ and obtain

$$
1+p^{2}=\frac{1}{C^{2} y} \quad \text { or } \quad p=\frac{d y}{d x}=\sqrt{\frac{1}{C^{2} y}-1}=\sqrt{\frac{c-y}{y}},
$$

with $c=C^{-2}$. In section 397 of E342 [13], Euler explains that the variables $x$ and $y$ should be separated, i.e.,

$$
\sqrt{\frac{y}{c-y}} \cdot d y=d x \quad \text { such that } \quad \int \sqrt{\frac{y}{c-y}} \cdot d y=x .
$$

The easiest method for such integrals are trigonometric substitutions, which Euler mentioned relatively late in E342 (in section 329). If we set $y=c \cdot \sin ^{2} u$ and profit from $1-\sin ^{2} u=\cos ^{2} u$, then the integral becomes an easy one and leads to the solution

$$
x=c u-\frac{c}{2} \sin 2 u, \quad y=c \cdot \sin ^{2} u=\frac{c}{2}-\frac{c}{2} \cos 2 u,
$$

so that "curvam quaesitam esse Cycloidem."

Numerical Solution. Whenever such an analytical solution is not possible, Euler proposed (in E342 [13], section 650) to compute the solution vero proxime assignare, by writing an equation such as (1.9) in the general form

$$
\frac{d y}{d x}=V(x, y), \quad \text { so that } \quad x_{i+1}=x_{i}+\Delta x, \quad y_{i+1}=y_{i}+\Delta x \cdot V\left(x_{i}, y_{i}\right)
$$




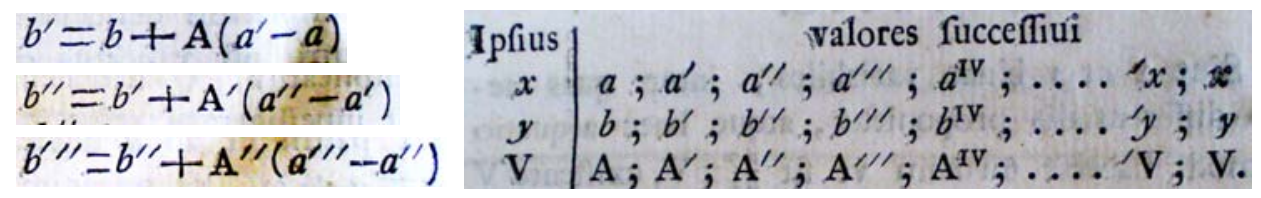

Fig. I.3 First publication of Euler's numerical method for differential equations.
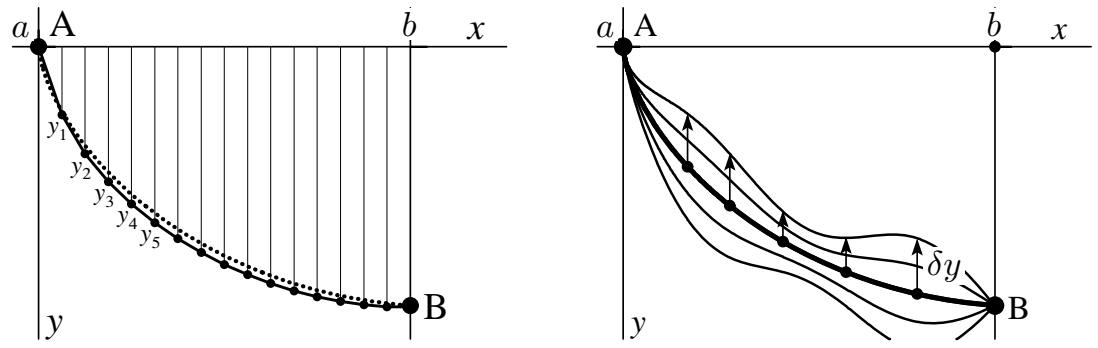

Fig. I.4 Numerical solution of the brachystochrone problem by Euler's method (exact solution dotted, left); Lagrange's variation $\epsilon \delta y$ of $y$ for $\epsilon=-1,-\frac{1}{2}, \frac{1}{2}, 1$ (right).

are, for $i=1,2,3, \ldots$, valores successivi of numerical approximations to the solution. The smaller we choose the "step size" $\Delta x$, the better will be the numerical approximation. We see in Figure 1.3 the first publication of this method, and in Figure 1.4 (left) the numerical result of computing 16 steps with this formula for the brachystochrone problem. ${ }^{3}$ This is the first of the so-called finite difference methods, which dominated scientific calculations for two centuries.

I.4. Joseph Louis de Lagrange. On August 12, 1755, the nineteen-year-old Ludovico de la Grange Tournier wrote to Vir amplissime atque celeberrime L. Euler, from whom Vir praestantissime atque excellentissime Lagrange received a kind and enthusiastic answer (September 6, 1755).

Lagrange's idea was the following: we perturb the optimal solution $y(x)$ by an arbitrary variation ${ }^{4} \delta y$. Only another 15 years later did it become clear to Euler [14] how "facilis" was the geometric meaning behind Lagrange's formalism: we add a fixed function $\delta(x)$ multiplied by $\epsilon$ to $y(x)$ (see Figure 1.4, right) and insert the result into (1.2). This integral must be minimal for all functions $\delta y(x)$ at $\epsilon=0$, i.e., the derivative of

$$
J(\varepsilon)=\int_{a}^{b} Z(x, y+\varepsilon \delta y, p+\varepsilon \delta p) d x \longrightarrow \min
$$

with respect to $\epsilon$ must be zero at $\epsilon=0$. We differentiate as follows:

$$
\left.\frac{\partial J(\varepsilon)}{\partial \varepsilon}\right|_{\varepsilon=0}=\int_{a}^{b}(N \cdot \delta y+P \cdot \delta p) d x=0 .
$$

\footnotetext{
${ }^{3}$ The formula does not work for $i=0$, because $V$ becomes infinite there. Such singularities must be treated separately.

${ }^{4}$ From here originates the name of the whole theory.
} 
Since $\delta p$ is the derivative of $\delta y$, we can integrate by parts:

$$
\int_{a}^{b}\left(N-\frac{d}{d x} P\right) \cdot \delta y \cdot d x=0 \quad \text { "weak solution." }
$$

Because $\delta y(a)=\delta y(b)=0$ (the end points of $y$ are fixed), the end-point contributions of (1.13) vanish. Since $\delta y$ is arbitrary, we conclude that for all $x$,

$$
N-\frac{d}{d x} P=0 \quad \text { "strong solution." }
$$

This last step, a trivial conclusion for the young discoverer, later caused the greatest difficulties.

The passage from the variational problem (1.11) by differentiation to (1.12), then by partial integration to (1.13), and finally to (1.14) is the central highway of variational calculus. In modern times (1.12) came to be called the "directional derivative" of $J$ and the function $\delta y(x)$ in (1.13) a "test function"; this equation is the starting point of the "Galerkin method." If we then manage to solve (1.14), we will have solved the original variational problem à la Euler. A very important application of the theory appeared in 1788 with Lagrange's Mécanique analytique, where the above "highway" connects the Lagrangian of a mechanical system (difference between potential and kinetic energy) to the differential equations of its motion. This later led to Hamiltonian mechanics.

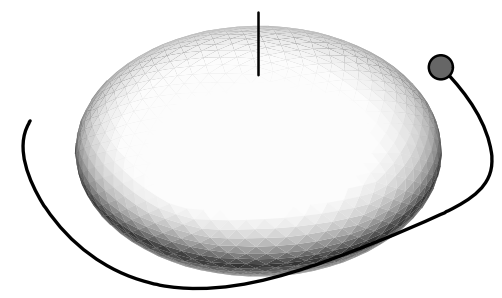

Fig. 2.I Attraction of a nonspherical celestial body.

2. Laplace's Equation and Dirichlet's Principle. Since Newton's Principia from 1687, it was known that celestial bodies move under the action of forces obeying the inverse square law, and since Euler's work (in particular, E112 from 1747) that their motion obeys second order differential equations with the corresponding term $f_{x} \approx \frac{x-\xi}{r^{3}}, r=\sqrt{(x-\xi)^{2}+(y-\eta)^{2}+(z-\zeta)^{2}}$. But this is only valid for pointwise, or at most perfectly spherical, bodies. If our body has another shape (see Figure 2.1), the attractive forces become

$$
f_{x}=\iiint \rho(\xi, \eta, \zeta) \frac{x-\xi}{r^{3}} d \xi d \eta d \zeta
$$

and similarly for $f_{y}$ and $f_{z}$, which are cumbersome expressions. Here Laplace (Théorie des attractions des spheroides et de la figure de la terre, 1785; see also Oeuvres I, Mécanique Céleste, p. 157) had the idea to introduce the potential function

$$
V=\iiint \rho(\xi, \eta, \zeta) \frac{1}{r} d \xi d \eta d \zeta, \quad \text { so that } \quad f_{x}=-\frac{\partial V}{\partial x}
$$


and similarly for $f_{y}$ and $f_{z}$. If we differentiate (2.1) once again with respect to $x$ (and $y$ and $z$, respectively), we find for $V$ the elegant expression

$$
\Delta V=\frac{\partial^{2} V}{\partial x^{2}}+\frac{\partial^{2} V}{\partial y^{2}}+\frac{\partial^{2} V}{\partial z^{2}}=0
$$

which bears the name Laplace's equation.

Soon after its formulation, this equation found many other important applications, not only in the heavens, but also down on earth:

- theory of stationary heat transfer (Fourier, 1822);

- theory of magnetism (Gauss and Weber in Göttingen, C.F. Gauss, Werke 5, p. $195,1839[16])$;

- theory of electric fields (W. Thomson, later Lord Kelvin [44], 1847);

- conformal mappings (Gauss, Werke IV, p. 189, 1825);

- in complex analysis (Cauchy, 1825, and Riemann [36], Thesis, 1851);

- irrotational fluid motion in two dimensions (Helmholtz, 1858).

All these applications led young Riemann to the following enthusiastic statement:

... eine vollkommen in sich abgeschlossene mathematische Theorie ..., welche ... fortschreitet, ohne zu scheiden, ob es sich um die Schwerkraft, oder die Electricität, oder den Magnetismus, oder das Gleichgewicht der Wärme handelt. (Manuscript of Riemann, Nov. 1850, Werke, p. 545.)

2.I. Conformal Maps and the Riemann Mapping Theorem. In his thesis [36] from 1851, Riemann founded geometric function theory, which studies theorems in complex analysis through elegant geometric considerations, and which was later perfected mainly through the work of Richard Courant (cf. the second part of Hurwitz and Courant [24]). The starting points are the Cauchy-Riemann differential equations for continuously differentiable functions $f(z)=u(x, y)+i v(x, y)$ with $z=x+i y$,

$$
\frac{\partial v}{\partial y}=\frac{\partial u}{\partial x} \frac{\partial u}{\partial y}=-\frac{\partial v}{\partial x}
$$

in Riemann's handwriting, ${ }^{5}$ which, when differentiated, give

$$
\Delta u=\frac{\partial^{2} u}{\partial x^{2}}+\frac{\partial^{2} u}{\partial y^{2}}=0 \quad \text { and } \quad \Delta v=\frac{\partial^{2} v}{\partial x^{2}}+\frac{\partial^{2} v}{\partial y^{2}}=0,
$$

i.e., $u$ and $v$ are harmonic. Furthermore, equations (2.4) tell us that the Jacobian in $\mathbb{R}^{2}$ of a continuously differentiable function is of the form

$$
\left(\begin{array}{ll}
\frac{\partial u}{\partial x} & \frac{\partial u}{\partial y} \\
\frac{\partial v}{\partial x} & \frac{\partial v}{\partial y}
\end{array}\right)=\left(\begin{array}{cc}
a & b \\
-b & a
\end{array}\right)=\text { Const } \cdot\left(\begin{array}{cc}
\cos \phi & \sin \phi \\
-\sin \phi & \cos \phi
\end{array}\right),
$$

i.e., it consists locally of a uniform scaling and an orthogonal rotation. Such everywhere angle-preserving functions are called conformal ("in kleinsten Theilen ähnlich"; see Figure 2.2).

Riemann Mapping Theorem. For any simply connected domain $\Omega$ there exists a bijective conformal mapping to the unit disk $f: \Omega \rightarrow B$. The point $z_{0}$ mapped to

\footnotetext{
${ }^{5}$ Courtesy of Prof. E. Neuenschwander, Riemanns Einführung in die Funktionentheorie, Göttingen, Vandenhoeck and Ruprecht, 1996.
} 

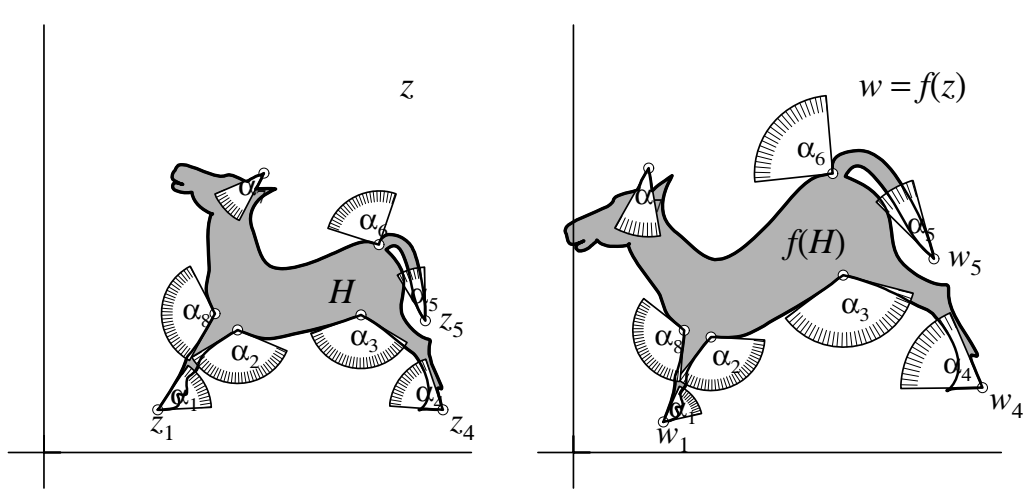

Fig. 2.2 A conformal mapping.

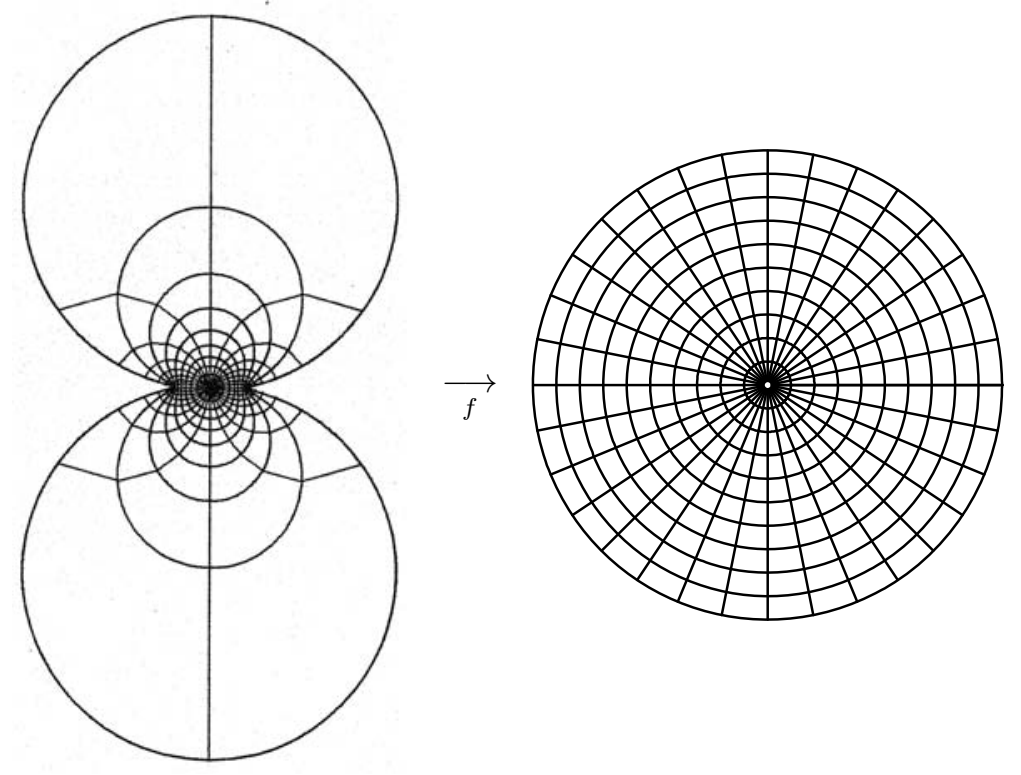

Fig. 2.3 Example for Riemann's mapping theorem for the domain $\Omega$ defined by $r(\phi) \leq(1-$ $\left.0.99 \cos ^{2} \phi\right)^{1 / 2}$ (computed by M. Gutknecht in 1975).

the origin can be freely chosen in the interior of $\Omega$, as well as the image of one point on the boundary. ("Zwei gegebene einfach zusammenhängende ebene Flächen können stets so aufeinander bezogen werden, dass jedem Punkte der einen Ein mit ihm stetig fortrückender Punkt der anderen entspricht und ihre entsprechenden kleinsten Theile ähnlich sind; ..."; Riemann [36], 1851, section 21, Werke, p. 40).

Riemann's proof of the mapping theorem. Riemann sketched a dubious proof of this audacious vision in the last two paragraphs of his thesis [36]. Some years later, in [37], he explained his ideas "in etwas veränderter Form." The theorem is illustrated in Figure 2.3, where $\Omega$ is an "inverse ellipse" defined by the radius $r(\phi) \leq\left(1-0.99 \cos ^{2} \phi\right)^{1 / 2} ;$ for $z_{0}$ we choose the origin. We then place a logarithm $\log \left(z-z_{0}\right)=\log r+i \phi$ at the point $z_{0}$. The level curves of its real part $u_{0}(x, y)$ are 
the concentric circles around $z_{0}$; the level curves of the imaginary part, orthogonal to the first ones, are the star-shaped rays out of $z_{0}$. The problem is that the boundary of $\Omega$ is normally not a level curve of $u_{0}$. We postulate that there exists an everywhere harmonic function $u_{1}(x, y)$ such that $u_{1}(x, y)=u_{0}(x, y)$ on the boundary $\partial \Omega$. The function $u(x, y):=u_{0}(x, y)-u_{1}(x, y)$ will be harmonic in $\Omega$ with the exception of the point $z_{0}$, where we have the logarithmic singularity, and it will be zero on $\partial \Omega$. By solving the differential equations (2.4), we complete $u(x, y)$ to a complex function $u(x, y)+i v(x, y)$. The exponential function of this function will then map $z_{0}$ to the origin and the boundary of $\Omega$ to the boundary of the circle.

These ideas of Riemann left scientists with much to do over the next century: clarifying the above proof, clarifying regularity conditions, developing the theory for more general domains, and developing better computational algorithms; see the last chapter of [24], Chapters 16 and 17 of Henrici's trilogy [20], and Gutknecht [19]. The main obstacle was the existence of the function $u_{1}$, which we will discuss in the next subsection.

\subsection{Dirichlet's Principle.}

Problem. Let $\Omega$ be a bounded domain and $F$ an arbitrary function defined on the boundary $\partial \Omega$. Find a function $w(x, y)$ with $\Delta w=0$, such that $w=F$ for $(x, y) \in \partial \Omega$ (see Figure 2.4 for an example).

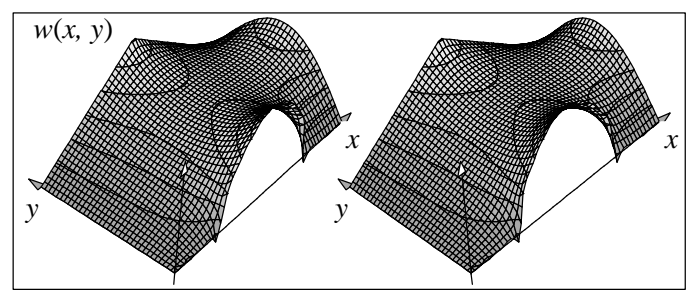

Fig. 2.4 Stereogram of the solution of $\Delta w=0,0 \leq x \leq \Phi, \Phi=1.618 \ldots, 0 \leq y \leq 1, F(x, 0)=$ $\sqrt{\left(-2 \cos \frac{2 \pi x}{L}\right)^{+}}, F(x, 1)=\min \left(\frac{\pi^{2} x}{4 L}, \frac{\pi^{2}(L-x)}{4 L}\right), F(0, y)=0, F(\Phi, y)=\sin \pi y$.

Riemann's solution [37]. This is based on the fact that the generalization of the variational problem (1.7) to higher dimensions is

$$
\iint_{\Omega}\left(\frac{1}{2}\left(\left(\frac{\partial w}{\partial x}\right)^{2}+\left(\frac{\partial w}{\partial y}\right)^{2}\right)-f \cdot w\right) d x d y \longrightarrow \min \Rightarrow-\frac{\partial^{2} w}{\partial x^{2}}-\frac{\partial^{2} w}{\partial y^{2}}=f
$$

This relation was discovered independently by Gauss [16], W. Thomson [44], and Dirichlet (in his lectures, which Riemann attended). The proof is precisely the same as above. Slightly more complicated is the step from (1.12) to (1.13): for one term we use partial integration with respect to $x$, which is straightforward, since the integration $d x$ is inside the integration $d y$. For the second term we use partial integration with respect to $y$; before doing this, we switch the order of integration:

Hierzu kann in vielen Fällen ... ein Princip dienen, welches Dirichlet zur Lösung dieser Aufgabe für eine der Laplace'schen partiellen Differentialgleichung genügende Function ... in seinen Vorlesungen ... seit einer Reihe von Jahren zu geben pflegt. (Riemann, 1857, Werke, p. 97) 
Riemann concludes that for all functions defined on $\Omega$ with the prescribed boundary values $F$, the integral

$$
J(w)=\iint_{\Omega} \frac{1}{2}\left(\left(\frac{\partial w}{\partial x}\right)^{2}+\left(\frac{\partial w}{\partial y}\right)^{2}\right) d x d y \quad \text { is always }>0 .
$$

Choose among these functions the one for which this integral has the smallest possible value!

In other words, we pass through the Euler-Lagrange highway $(1.11) \Rightarrow(1.14)$ in the opposite direction $(1.11) \Leftarrow(1.14)$. In contrast to "Euler's world," here the solution of the differential equation (1.14) is impossible, whereas the variational problem (1.11) appears "trivial." From here originate the terms "Dirichlet's principle" and "Dirichlet boundary conditions."

Weierstrass's Critique. Soon afterwards some people started to mistrust this "brave new world," the most serious critic being Weierstrass [49] with the counterexample

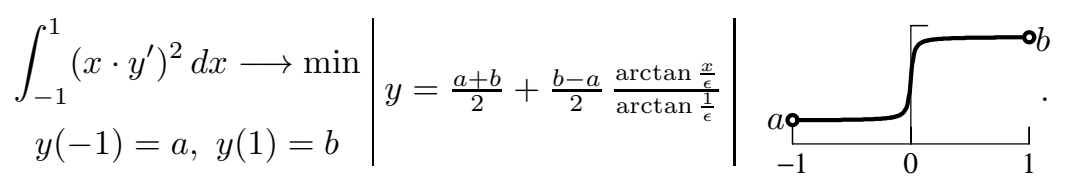

The factor $x$ in the integral allows $y^{\prime}$ to do anything close to the origin, and the solution of the problem becomes discontinuous ("Die Dirichlet'sche Schlussweise führt also in dem betrachteten Falle offenbar zu einem falschen Resultat.")

F. Klein (Entw. Math., 19, Jahrh., Chelsea, 1967, p. 264) reports that Riemann replied to Weierstrass, "my theorems remain nevertheless true" ("meine Existenztheoreme sind trotzdem richtig"), and that Helmholtz declared "for us physicists Dirichlet's principle remains a proof" ("für uns Physiker bleibt das Dirichletsche Prinzip ein Beweis").

Proof without Dirichlet's Principle. The majority of mathematicians, however, abandoned Riemann's idea and started to look for alternative methods of proof, such as the alternating method invented by H. A. Schwarz (1870, Crelle 74, 1872). This method is based on the fact that for rectangles, as well as circles, the existence of the solution is assured by Fourier series methods. A more complicated domain is represented as an overlapping union of such simple domains:

Solve alternatively in $\Omega_{1}$ and $\Omega_{2}$; new boundary values on dotted curves; prove that iteration converges; add third, fourth domain, etc.

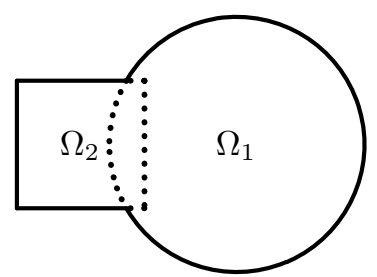

Revival of Dirichlet's Principle by Hilbert. Precisely half a century after Riemann's thesis, D. Hilbert undertook the task of putting Dirichlet's principle onto a new basis [21,22]. Certainly, Weierstrass's counterexample is embarrassing, but the integral in (2.9) is not the same as in (2.8). So Hilbert managed, in an extraordinary tour de force, to establish a way of proving the existence of $u$ directly from the properties of the integral (2.8). A couple of theses written under Hilbert's supervision, including Courant's $[8,9]$, then improved this theory by making it simpler and more 
complete. These discussions became another motivation for W. Ritz to develop his method.

Das Dirichletsche Prinzip verdankte seinen Ruhm der anziehenden Einfachheit seiner mathematischen Grundidee, dem unleugbaren Reichtum der möglichen Anwendungen . . . und der ihm innewohnenden Überzeugungskraft.

(D. Hilbert)

Mittlerweile war das verachtete und scheintote Dirichletsche Prinzip durch Hilbert wieder zum Leben erweckt worden; ... (Hurwitz and Courant [24, p. 392])

3. The Elastic Plate. The main motivation for Ritz was the announcement of the Prix Vaillant for 1907 by the Academy of Science in Paris (see Figure 3.1), published in vol. 53 of Journal für Mathematik und Physik, p. 65. This announcement was sent to him by his friend Paul Ehrenfest on a postcard, in order for the "Scheusaltheorie" of Ritz's thesis to find a new application. The deformation of an elastic plate under an external force was a very difficult problem at that time; it was first considered by Sophie Germaine in several articles (1811-1815), ${ }^{6}$ to which Lagrange and Poisson added corrections and improvements. The definitive breakthrough was achieved in a long article by Kirchhoff [25] (1850) in the form of the differential equation

$$
\Delta \Delta w=\frac{\partial^{4} w}{\partial x^{4}}+2 \frac{\partial^{4} w}{\partial x^{2} \partial y^{2}}+\frac{\partial^{4} w}{\partial y^{4}}=f(x, y),
$$

to which suitable boundary conditions must be added. If the plate is assumed to be clamped on all sides, we have

$$
w=0 \quad \text { and } \quad \frac{\partial w}{\partial n}=0 \quad \text { on } \partial \Omega
$$

\section{Preisaufgaben der Académie des Sciences de Paris aus der angewandten} Mathematik und Physik.

\section{Fïr 1907. ${ }^{1}$ )}

Prix Vaillant (4000 fr.): Perfectionner en un point important le problème d'Analyse relatif à l'équilibre des plaques élastiques encastrées, e'est-à-dire le problème de l'intégration de l'équation

$$
\frac{\partial^{4} u}{\partial x^{4}}+2 \frac{\partial^{4} u}{\partial x^{2} \partial y^{2}}+\frac{\partial^{4} u}{\partial y^{4}}=f(x, y)
$$

avec les conditions que la fonction $u$ et sa dérivée suivant la normale au contour de la plaque soient nulles. Examiner plus spécialement le cas d'un contour rectangulaire. - Les Mémoires devront être envoyés au Secrétariat avant le $1^{\text {er }}$ janvier 1907 .

Fig. 3.I Announcement for the Prix Vaillant in Journal für Mathematik und Physik.

Ritz had worked with many such problems in his thesis, where he tried to explain the Balmer series in spectroscopy (1902); it therefore appeared to him that he had a good chance of succeeding in this competition.

\footnotetext{
${ }^{6}$ This research was motivated by a visit of Chladni to Paris in 1808 .
} 
4. Ritz's Treatment of the Plate and Dirichlet's Principle. We now come to the publication in the Crelle Journal [38],

\section{Über eine neue Methode zur Lösung gewisser Variationsprobleme der mathematischen Physik. \\ Von Herrn Walter Ritz in Göttingen.}

through which Ritz achieved immortality. Following Riemann, we proceed on the Euler-Lagrange highway backwards and arrive, starting from (3.1), at the variational problem

$$
J=\iint_{\Omega}\left(\frac{1}{2}\left(\left(\frac{\partial^{2} w}{\partial x^{2}}\right)^{2}+2\left(\frac{\partial^{2} w}{\partial x^{2}}\right)\left(\frac{\partial^{2} w}{\partial y^{2}}\right)+\left(\frac{\partial^{2} w}{\partial y^{2}}\right)^{2}\right)-f \cdot w\right) d x d y \longrightarrow \min
$$

or

$$
J=\iint_{\Omega}\left(\frac{1}{2}(\Delta w)^{2}-f \cdot w\right) d x d y \longrightarrow \min .
$$

The standard procedure ("wie man ohne weiteres einsieht") transforms term by term the formula (4.1) to (3.1); we just have to perform each time two integrations by parts, so that the minus sign in (2.7) disappears again.

4.I. Ritz's Method. The main idea is the following: we choose a sequence of functions

$$
\psi_{1}(x, y), \psi_{2}(x, y), \psi_{3}(x, y), \psi_{4}(x, y), \ldots
$$

and try to approximate the solution of (4.1) as a linear combination ${ }^{7}$

$$
w(x, y)=a_{1} \psi_{1}(x, y)+a_{2} \psi_{2}(x, y)+\cdots+a_{m} \psi_{m}(x, y),
$$

with the coefficients $a_{1}, a_{2}, \ldots, a_{m}$ to be determined. The quality of the method depends, of course, on a good choice of these functions. For example, if we assume $\Omega$ to be a square, one choice discussed by Ritz is

$$
\begin{aligned}
& \psi_{1}(x, y)=\left(1-x^{2}\right)^{2}\left(1-y^{2}\right)^{2}, \\
& \psi_{2}(x, y)=\left(1-x^{2}\right)^{2}\left(1-y^{2}\right)^{2}\left(x^{2}+y^{2}\right), \\
& \psi_{3}(x, y)=\left(1-x^{2}\right)^{2}\left(1-y^{2}\right)^{2}\left(x^{4}+y^{4}\right), \\
& \psi_{4}(x, y)=\left(1-x^{2}\right)^{2}\left(1-y^{2}\right)^{2} x^{2} y^{2}, \\
& \psi_{5}(x, y)=\left(1-x^{2}\right)^{2}\left(1-y^{2}\right)^{2}\left(x^{6}+y^{6}\right), \\
& \psi_{6}(x, y)=\left(1-x^{2}\right)^{2}\left(1-y^{2}\right)^{2}\left(x^{4} y^{2}+x^{2} y^{4}\right) \ldots
\end{aligned}
$$

Each of these $\psi_{i}$ contains the factor $\left(1-x^{2}\right)^{2}\left(1-y^{2}\right)^{2}$ in order to ensure the validity of the boundary conditions (3.2) for any choice of the $a_{i}$. We suppose $f(x, y)=1$ and conclude by symmetry that odd powers of $x$ or $y$ will not appear. For the same reason, the terms containing $x^{2}$ and $y^{2}$ will have the same coefficient, so we simplify our calculations by collecting such equal terms into one function $\psi$. Another good property of our basis is that, for $m \rightarrow \infty$, it contains all (symmetric) polynomials; therefore, they are able, by Weierstrass's approximation theorem, to approach any (symmetric) solution function $w$. This will be important for establishing convergence of the method.

\footnotetext{
${ }^{7}$ See the memorial plate in honor of Ritz at the Collège des Creusets, Sion, Switzerland.
} 
If we insert the expression (4.4) into (4.2), we obtain a finite-dimensional expression in $a_{1}, a_{2}, \ldots, a_{m}$. By chance, $J$ in (4.2) contains only quadratic and linear terms of $w$. Hence, if we multiply out all the terms, we obtain a finite-dimensional quadratic function

$$
J_{m}=\frac{1}{2} \sum_{i, j=1}^{m} k_{i j} a_{i} a_{j}-\sum_{i=1}^{m} b_{i} a_{i}
$$

with

$$
k_{i j}=\int_{-1}^{1} \int_{-1}^{1} \Delta \psi_{i} \cdot \Delta \psi_{j} d x d y, \quad b_{i}=\int_{-1}^{1} \int_{-1}^{1} \psi_{i} \cdot f d x d y
$$

Differentiating (4.6) with respect to $a_{\ell}$, for $\ell=1,2, \ldots, m$, we find that $J_{m}$ is minimal if

$$
\sum_{j=1}^{m} k_{\ell j} a_{j}=b_{\ell} .
$$

This is a linear system which, in theory, is easily solvable. In practice, however, the system is very tedious to solve: for $m=6$, obtaining just one of the $21 k$-values would require us to compute

$$
\begin{aligned}
\Delta \psi_{6} \cdot \Delta \psi_{6}= & 8 x^{2}\left(1-y^{2}\right)^{2}\left(x^{4} y^{2}+x^{2} y^{4}\right) \\
& -8\left(1-x^{2}\right)\left(1-y^{2}\right)^{2}\left(4 x^{3} y^{2}+2 x y^{4}\right) x \\
& -4\left(1-x^{2}\right)\left(1-y^{2}\right)^{2}\left(x^{4} y^{2}+x^{2} y^{4}\right) \\
& +\left(1-x^{2}\right)^{2}\left(1-y^{2}\right)^{2}\left(12 x^{2} y^{2}+2 y^{4}\right) \\
& +8\left(1-x^{2}\right)^{2} y^{2}\left(x^{4} y^{2}+x^{2} y^{4}\right) \\
& -8\left(1-x^{2}\right)^{2}\left(1-y^{2}\right)\left(2 x^{4} y+4 x^{2} y^{3}\right) y \\
& -4\left(1-x^{2}\right)^{2}\left(1-y^{2}\right)\left(x^{4} y^{2}+x^{2} y^{4}\right) \\
& +\left(1-x^{2}\right)^{2}\left(1-y^{2}\right)^{2}\left(2 x^{4}+12 x^{2} y^{2}\right)
\end{aligned}
$$

and then $\int_{-1}^{1} \int_{-1}^{1} \Delta \psi_{6} \cdot \Delta \psi_{6} d x d y=\frac{3052404736}{6898776885}$. We can understand why Ritz did not use this particular basis to demonstrate his method numerically. We, however, have modern computers and find the system

\begin{tabular}{rrrrrr|l}
53.49878 & 9.72705 & 2.13385 & 0.54039 & 0.63739 & 0.30484 & 1.13778 \\
9.72705 & 21.94822 & 10.91868 & 1.74588 & 5.99358 & 1.25965 & 0.32508 \\
2.13385 & 10.91868 & 9.63314 & 0.90947 & 7.10042 & 1.01770 & 0.10836 \\
0.54039 & 1.74588 & 0.90947 & 0.47237 & 0.51468 & 0.39553 & 0.02322 \\
0.63739 & 5.99358 & 7.10042 & 0.51468 & 6.32258 & 0.73117 & 0.04925 \\
0.30484 & 1.25965 & 1.01770 & 0.39553 & 0.73117 & 0.44246 & 0.01548
\end{tabular}

If we set $m=1$, only $k_{11} a_{1}=b_{1}$ has to be considered and we obtain by a simple division

$$
a_{1}=1.13778 / 53.49878=0.021267 .
$$

The solution $w=a_{1} \psi_{1}$ is drawn at the top of Figure 4.1 and has an error of $4 \%$. If we also include polynomial terms of degree 6 , i.e., if we set $m=2$, we have a linear system of two equations to solve and obtain

$$
a_{1}=0.02020, \quad a_{2}=0.00586
$$



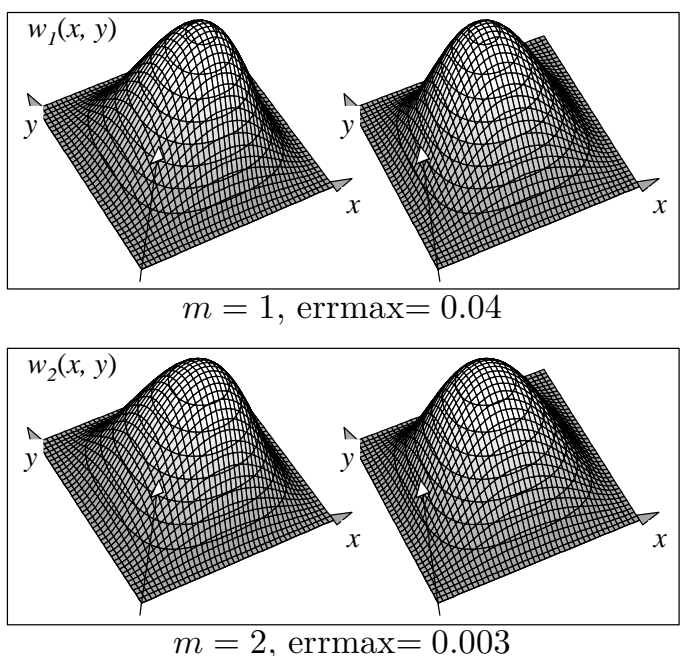

Fig. 4.I Solutions of the plate problem for $m=1$ and $m=2$.

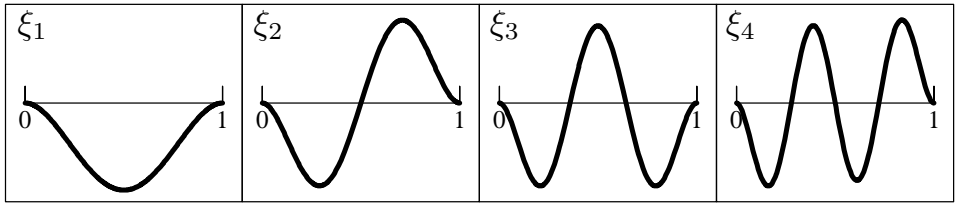

Fig. 4.2 One-dimensional elastic curves.

which reduces the error to $0.3 \%$ (bottom of Figure 4.1). Taking into account also 8th-degree terms $(m=4)$ leads to a relative error of $10^{-5}$ with precisely the same graphical representation as for $m=2$. For $m=6$ the solutions are

$$
\begin{array}{ll}
a_{1}=0.02025, \quad a_{2}=0.00521, & a_{3}=0.00028, \\
a_{4}=0.00612, \quad a_{5}=-0.00002, & a_{6}=0.00012 .
\end{array}
$$

4.2. A Basis Using One-Dimensional Elastic Curves. As satisfactory as the above numerical results are, they are not suitable for hand calculations. Instead of these polynomials, Ritz suggested using the normal modes of the clamped rod:

$$
\xi^{(4)}=K^{4} \cdot \xi, \quad \xi(0)=\xi(1)=0, \quad \xi^{\prime}(0)=\xi^{\prime}(1)=0 .
$$

Ritz cited Lord Rayleigh [41], in The Theory of Sound, p.174, for the formulas; however, they had already been studied extensively by Euler in Additamentum I, De curvis elasticis of [12], sections 68-97.

Standard methods for differential equations with constant coefficients lead, together with the first three boundary conditions, to the formula

$$
\xi_{n}(x)=\cos K_{n} x-\cosh K_{n} x-\left(\sin K_{n} x-\sinh K_{n} x\right) \frac{\cos K_{n}-\cosh K_{n}}{\sin K_{n}-\sinh K_{n}} .
$$

The condition $\xi^{\prime}(1)=0$ then gives $\cos K_{n} \cosh K_{n}=1$, which determines the discrete values of $K_{n}$ as follows (see Figure 4.2):

$$
K_{1}=4.7300, \quad K_{2}=7.8532, \quad K_{3}=10.9956, \quad K_{4}=14.1372, \ldots
$$


Because $\cosh K$ tends to infinity very rapidly, $K_{n}$ will also quickly approach the roots of the cosine, i.e., $K_{n} \approx\left(n+\frac{1}{2}\right) \pi$.

Taking into account again the symmetry of the solution, we use the basis

$$
\begin{array}{ll}
\psi_{1}(x, y)=\xi_{1}(x) \xi_{1}(y), & \psi_{2}(x, y)=\xi_{1}(x) \xi_{3}(y)+\xi_{3}(x) \xi_{1}(y) \\
\psi_{3}(x, y)=\xi_{3}(x) \xi_{3}(y), & \psi_{4}(x, y)=\xi_{1}(x) \xi_{5}(y)+\xi_{5}(x) \xi_{1}(y), \ldots
\end{array}
$$

The advantages of this basis are that

1. we only have one defining formula (4.14) for every $n$;

2. using integration by parts, the condition (4.13) leads to easy formulas for the integrals (4.7); and

3. the linear system (4.8) becomes strongly diagonally dominant.

$$
\begin{aligned}
& l \cdot 431,5=\underline{651,8} a_{11}-239,2 a_{13}+94,7 a_{33}-188 a_{15}+148 a_{35}+58 a_{55} \\
& l \cdot 188,5=-119,6 a_{11}+\underline{8867} a_{13}-961 a_{33}-226 a_{15}-515 a_{35}+186 a_{55} \\
& l \cdot 82,7=94,6 a_{11}-1922 a_{13}+\underline{24390} a_{33}+474 a_{15}-4820 a_{35}+592 a_{55} \\
& l \cdot 120,0=-93,8 a_{11}-226 a_{13}+237 a_{33}+\underline{48100} a_{15}-2370 a_{35}-2015 a_{55} \\
& l \cdot 52,5=74,3 a_{11}-515 a_{13}-2410 a_{33}-2370 a_{15}+\underline{78600} a_{35}-6420 a_{55} \\
& l \cdot 33,5=58 a_{11}+372 a_{13}+592 a_{33}-4030 a_{15}-12840 a_{35}+\underline{158500} a_{55}
\end{aligned}
$$

It can thus be solved easily ("der Rechenschieber angewandt werden kann...") by a sort of "Gauss-Seidel" iteration. ("Eine direkte Lösung durch Determinanten würde 5stellige Logarithmentafeln erfordern.") In this way, Ritz obtained the solutions

$$
\begin{aligned}
w_{1}(x, y)= & 0.6620 \xi_{1}(x) \xi_{1}(y) \\
w_{2}(x, y)= & 0.6727 \xi_{1}(x) \xi_{1}(y)+0.0307\left(\xi_{1}(x) \xi_{3}(y)\right. \\
& \left.+\xi_{3}(x) \xi_{1}(y)\right)+0.0031 \xi_{3}(x) \xi_{3}(y) \\
w_{3}(x, y)= & 0.6740 \xi_{1}(x) \xi_{1}(y)+0.0380\left(\xi_{1}(x) \xi_{3}(y)+\xi_{3}(x) \xi_{1}(y)\right) \\
& +0.0032 \xi_{3}(x) \xi_{3}(y)+0.0040\left(\xi_{1}(x) \xi_{5}(y)+\xi_{5}(x) \xi_{1}(y)\right) \\
& +0.0004\left(\xi_{3}(x) \xi_{5}(y)+\xi_{5}(x) \xi_{3}(y)\right)+0.0000 \xi_{5}(x) \xi_{5}(y),
\end{aligned}
$$

whose graphical representation is not so different from those in Figure 4.1.

Theorem of Existence And Convergence. Based on

- a careful study of speed of convergence based on the asymptotic values of $K_{n}$, allowing the exchange of differentiations and limits;

- Weierstrass's approximation theorem; and

- a modification of a lemma from Hilbert's proof (1901),

Ritz managed, in paragraphs 3, 4, and 5 of his paper, to prove rigorously that the $w_{m}(x, y)$ converge to a function $w(x, y)$ that solves the minimization problem.

4.3. Dirichlet's Principle. In the second part of [38], Ritz applied his proofs to Dirichlet's problem (see section 2.2)

$$
\Delta w=0,\left.\quad w\right|_{\partial \Omega}=F .
$$

In order to have the boundary values equal to 0 , we subtract $F$ from $w$ and obtain a problem of the type

$$
-\Delta w=f,\left.\quad w\right|_{\partial \Omega}=0 .
$$




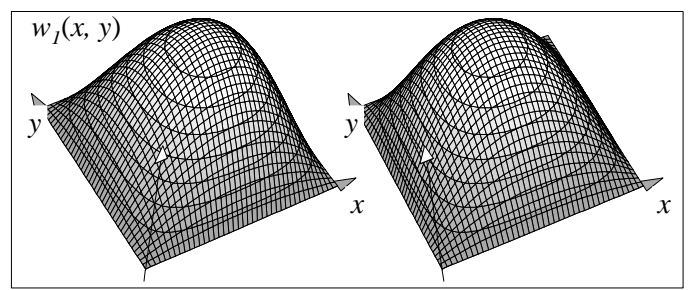

$m=1$, errmax $=0.05$

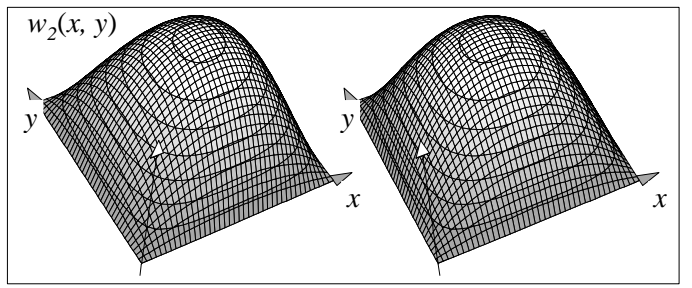

$m=2$, errmax $=0.01$

Fig. 4.3 Solutions for Dirichlet's principle.

Inserting (4.4) into (2.7), we obtain

$$
k_{i j}=\int_{-1}^{1} \int_{-1}^{1}\left(\frac{\partial \psi_{i}}{\partial x} \frac{\partial \psi_{j}}{\partial x}+\frac{\partial \psi_{i}}{\partial y} \frac{\partial \psi_{j}}{\partial y}\right) d x d y, \quad b_{i}=\int_{-1}^{1} \int_{-1}^{1} \psi_{i} \cdot f d x d y
$$

instead of (4.7). Ritz then proceeded to prove once again the existence and convergence of his method, but he did not show numerical examples; for the square they would have been too simple.

Let us show them here, by modifying the basis functions according to the new boundary condition as

$$
\begin{aligned}
& \psi_{1}(x, y)=\left(1-x^{2}\right)\left(1-y^{2}\right) \\
& \psi_{2}(x, y)=\left(1-x^{2}\right)\left(1-y^{2}\right)\left(x^{2}+y^{2}\right) \\
& \psi_{3}(x, y)=\left(1-x^{2}\right)\left(1-y^{2}\right)\left(x^{4}+y^{4}\right) \\
& \psi_{4}(x, y)=\left(1-x^{2}\right)\left(1-y^{2}\right) x^{2} y^{2} \\
& \psi_{5}(x, y)=\left(1-x^{2}\right)\left(1-y^{2}\right)\left(x^{6}+y^{6}\right) \\
& \psi_{6}(x, y)=\left(1-x^{2}\right)\left(1-y^{2}\right)\left(x^{4} y^{2}+x^{2} y^{4}\right) \ldots
\end{aligned}
$$

and obtain, proceeding as above, the solutions

$$
\begin{array}{ll}
\text { for } m=1: & a_{1}=0.3125 ; \\
\text { for } m=2: & a_{1}=0.2922, \quad a_{2}=0.05923 .
\end{array}
$$

These solutions are drawn in Figure 4.3. Again, the higher order terms have little effect on the graphic representation of the function. One observes that for each increase of the degree by a factor of 2 , the error decreases by a factor of 4 .

5. Ritz Computes Chladni Figures. In 1787, Ernst Florence Friedrich Chladni, a musician and physicist from Wittenberg close to Leipzig, made an extraordinary discovery [5]: he noticed that when he tried to excite a metal plate with the bow of his violin, he could make sounds of different pitch, depending on where he touched the 

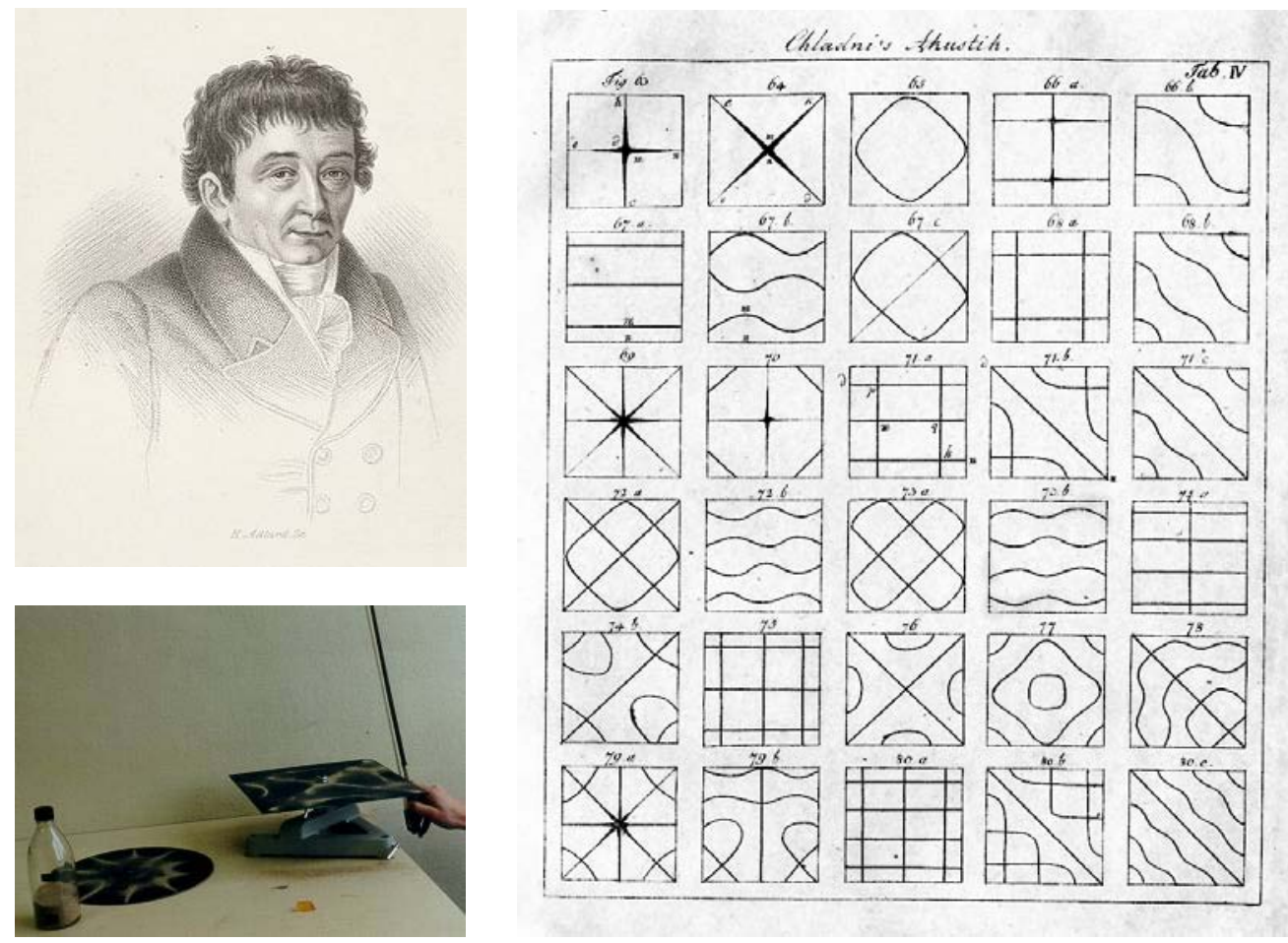

Fig. 5.I Ernst Florens Friedrich Chladni and his famous experiment. On the right, the drawings by Chladni of the figures he managed to create using his violin bow to excite an iron plate with some sand on it.

plate with the bow; see the experimental setup shown in the bottom left of Figure 5.1. The plate itself was fixed only in the center, and when there was some dust or sand on the plate, for each pitch a beautiful pattern appeared. Chladni carefully collected all the figures he was able to create, and made drawings of each and every one; see Figure 5.1 on the right. These figures, now called Chladni figures after their inventor, attracted great attention among scientists and laymen alike, because of their intriguing beauty. We show in Figure 5.2 more recent high-tech experiments from Munich and San Diego, which recreate Chladni's experiments with very high accuracy. We invite the reader to compare those results with the historical drawings of Chladni to find similarities and differences.

5.I. The Mathematical Model for Chladni Figures. For the vibrating plate, the equations (3.1) and (3.2) of Kirchhoff [25] (1850) are modified as follows. Chladni figures on a square plate correspond to eigenpairs (eigenvalues and corresponding eigenfunctions) of the biharmonic operator

$$
\Delta^{2} w=\lambda w \quad \text { in } \Omega:=(-1,1)^{2},
$$

with the free boundary conditions

$$
\begin{aligned}
& \frac{\partial}{\partial x}\left(\frac{\partial^{2} w}{\partial x^{2}}+(2-\mu) \frac{\partial^{2} w}{\partial y^{2}}\right)=0, \frac{\partial^{2} w}{\partial x^{2}}+\mu \frac{\partial^{2} w}{\partial y^{2}}=0, \quad x=\{-1,1\}, \\
& \frac{\partial}{\partial x}\left(\frac{\partial^{2} w}{\partial y^{2}}+(2-\mu) \frac{\partial^{2} w}{\partial x^{2}}\right)=0, \quad \frac{\partial^{2} w}{\partial y^{2}}+\mu \frac{\partial^{2} w}{\partial x^{2}}=0, \quad y=\{-1,1\},
\end{aligned}
$$



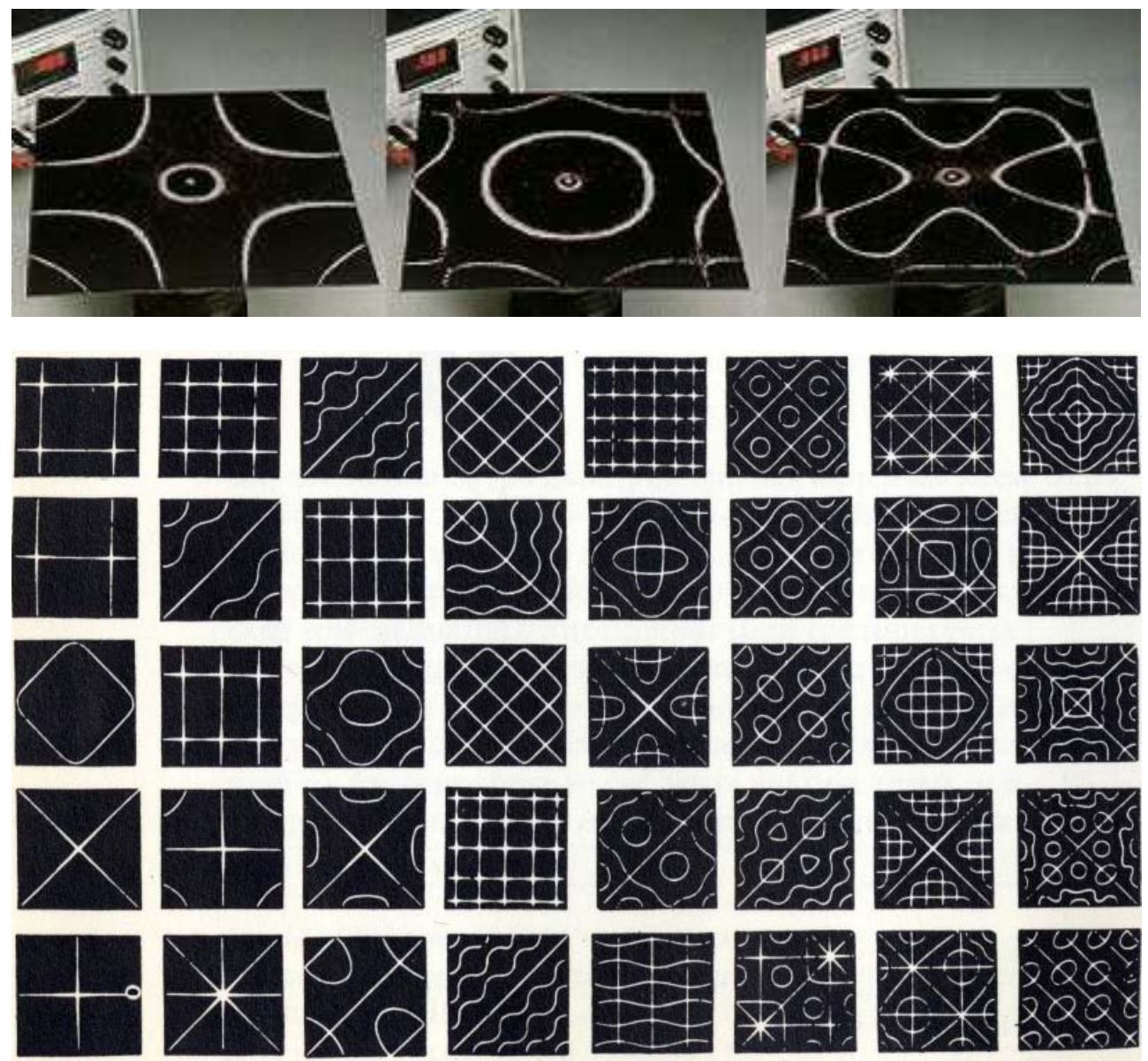

Fig. $\mathbf{5 . 2}$ Creation of Chladni figures in a modern laboratory environment in Munich and San Diego.

where $\mu$ here is the elasticity constant. Even before the correct mathematical model had been established, Wheatstone [50] had tried in 1833 to approximate Chladni figures using sine and cosine functions. ${ }^{8}$ Kirchhoff, who came up with the correct mathematical model in 1850, also managed to solve the Chladni problem for the special case of a circular plate, which, due to symmetry, is much easier to handle. For other configurations, the partial differential eigenvalue problem (5.1) with the free boundary conditions (5.2) simply proved to be too difficult to solve. ${ }^{9}$ There were even erroneous attempts: based on experiments performed by the master violin maker König [26] in 1864, which suggested that Chladni figures can only contain straight lines, Tanaka tried in 1887 to obtain solutions by integration starting from straight

\footnotetext{
${ }^{8}$ Ritz: “. . . dass es sich hier nur um einen in besonderen Fällen anwendbaren Kunstgriff handelt."

${ }^{9}$ Ritz: "Die von Kirchhoff erhaltene partielle Differentialgleichung ist vierter Ordnung, und es müssen am Rande zwei Differentialausdrücke dritter und zweiter Ordnung verschwinden, die von einer Elastizitätskonstante[n] abhängen. Die grosse hieraus sich ergebende Komplikation des Problems erklärt es hinreichend, dass die Lösung bis jetzt nur im Falle des Kreises (Kirchhoff) gefunden wurde, wobei sich ein sehr befriedigender Anschluss an die Erfahrung ergab. Die Klangfiguren bestehen hier nur aus konzentrischen Kreisen und aus Radien."
} 
lines. ${ }^{10}$ In the case of clamped boundaries, the problem greatly simplifies, and Voigt [48] found the general solution in 1893 for a rectangular plate with two or four clamped boundaries by elementary integration. Toward the end of the 19th century, the great expert in sound, John William Strutt, later Baron Rayleigh, summarized the situation in [41]: "The Problem of a rectangular plate, whose edges are free, is one of great difficulty, and has for the most part resisted attack."

5.2. Ritz's Computation of Chladni Figures. In his second groundbreaking paper [39], Walther Ritz presents and analyzes his own method in order to compute Chladni figures: instead of trying to solve the partial differential eigenvalue problem (5.1)-(5.2) directly, he proposes to use the principle of energy minimization, from which the equations were derived, ${ }^{11}$ and thus he considers the functional

$$
J(w):=\int_{-1}^{1} \int_{-1}^{1}\left[\left(\frac{\partial^{2} w}{\partial x^{2}}\right)^{2}+\left(\frac{\partial^{2} w}{\partial y^{2}}\right)^{2}+2 \mu \frac{\partial^{2} w}{\partial x^{2}} \frac{\partial^{2} w}{\partial y^{2}}+2(1-\mu)\left(\frac{\partial^{2} w}{\partial x \partial y}\right)^{2}\right]
$$

According to the minimization principle, the solution $w$ of (5.1)-(5.2) is a minimum of the constrained problem

$$
J(w) \rightarrow \min , \quad \int_{-1}^{1} \int_{-1}^{1} w^{2} d x d y=\text { const. }
$$

and, from this minimization problem, one can again obtain the partial differential eigenvalue problem by simply using the central highway of variational calculus.

Even though Ritz explains his new method using the concrete example of Chladni figures on a square plate, he points out that his new method is completely general and could be applied to plates of arbitrary shapes, provided the basis functions are well chosen. ${ }^{12}$ The fundamental idea of Ritz's new method was to search for an approximate solution of the problem as a combination of well-chosen so-called coordinate functions ("Grundfunktionen") of the form

$$
w_{s}=\sum_{m=0}^{s} A_{m} w_{m}(x, y)
$$

If a simple solution is sought, for example, the lowest pitch, Ritz points out that one could simply choose polynomials for the basis functions $w_{m}(x, y) \cdot{ }^{13}$ For higher eigenmodes, a better choice that leads to more accuracy is to use the same coordinate

\footnotetext{
${ }^{10}$ Ritz: “... Tanaka glaubt, allgemeinere und strengere Formeln zu erhalten. Dies ist aber schon deswegen nicht der Fall, weil übersehen ist, dass eine Randbedingung die Lösung gar nicht bestimmt."

${ }^{11}$ Ritz: "Das wesentliche der neuen Methode besteht darin, dass nicht von den Differentialgleichungen und Randbedingungen des Problems, sondern direkt vom Prinzip der kleinsten Wirkung ausgegangen wird, aus welchem ja durch Variation jene Gleichungen und Bedingungen gewonnen werden können."

${ }^{12}$ Ritz: "Im folgenden entwickle ich am Beispiel der quadratischen Platten mit freien Rändern eine neue Integrationsmethode, die ohne wesentliche Änderungen auch auf rechteckige Platten angewandt werden kann, sei es mit freien, sei es auch mit teilweise oder ganz eingespannten oder gestützten Rändern. Theoretisch ist die Lösung in ähnlicher Weise sogar für eine beliebige Gestalt der Platte möglich; eine genaue Berechnung einer grösseren Anzahl von Klangfiguren, wie sie im folgenden für den klassischen Fall der quadratischen Scheibe durchgeführt ist, wird aber nur bei geeigneter Wahl der Grundfunktionen, nach welchen entwickelt wird, praktisch ausführbar."

${ }^{13}$ Ritz: "Für den Grundton, wofern grosse Genauigkeit nicht gefordert wird, führt das Verfahren für die meisten Platten durch den Ansatz von Polynomen zum Ziel."
} 
functions as in the previous section: ${ }^{14}$

$$
\begin{aligned}
& w_{m n}=u_{m}(x) u_{n}(y)+u_{m}(y) u_{n}(x), \\
& w_{m n}^{\prime}=u_{m}(x) u_{n}(y)-u_{m}(y) u_{n}(x),
\end{aligned}
$$

where $u_{m}(x)$ are the known eigenfunctions of a free one-dimensional bar,

$$
\frac{d^{4} u_{m}}{d x^{4}}=k_{m}^{4} u_{m}, \quad \text { with } \frac{d^{2} u_{m}}{d x^{2}}=0, \frac{d^{3} u_{m}}{d x^{3}}=0 \text { at } x=\{-1,1\} .
$$

These conditions lead to the functions

$$
u_{m}=\left\{\begin{array}{lll}
\frac{\cosh k_{m} \cos k_{m} x+\cos k_{m} \cosh k_{m} x}{\sqrt{\cosh ^{2} k_{m}+\cos ^{2} k_{m}}}, & \tan k_{m}+\tanh k_{m}=0, & m \text { even } \\
\frac{\sinh k_{m} \sin k_{m} x+\sin k_{m} \sinh k_{m} x}{\sqrt{\sinh ^{2} k_{m}-\sin ^{2} k_{m}}}, & \tan k_{m}-\tanh k_{m}=0, & m \text { odd }
\end{array}\right.
$$

Ritz approximation of the solution then takes the form

$$
w_{s}:=\sum_{m=0}^{s} \sum_{n=0}^{s} A_{m n} u_{m}(x) u_{n}(y)
$$

In order to determine the coefficients $A_{m n}$, we again insert this solution into the functional (5.3), and we require that the resulting functional

$$
\int_{-1}^{1} \int_{-1}^{1}\left[\left(\frac{\partial^{2} w_{s}}{\partial x^{2}}\right)^{2}+\left(\frac{\partial^{2} w_{s}}{\partial y^{2}}\right)^{2}+2 \mu \frac{\partial^{2} w_{s}}{\partial x^{2}} \frac{\partial^{2} w_{s}}{\partial y^{2}}+2(1-\mu)\left(\frac{\partial^{2} w_{s}}{\partial x \partial y}\right)^{2}\right] d x d y
$$

is minimal ${ }^{15}$ under the constraint

$$
U\left(w_{s}\right):=\int_{-1}^{1} \int_{-1}^{1} w_{s}^{2} d x d y=\text { const. }=: C .
$$

In this approximate problem, we only need to determine a finite number of coefficients $A_{m n}$.

In order to express the functional $J\left(w_{s}\right)$ in terms of the coefficients $A_{m n}$, we have to evaluate several integral terms. The first one is

$$
\begin{array}{r}
\int_{-1}^{1} \int_{-1}^{1}\left(\frac{\partial^{2} w_{s}}{\partial x^{2}}\right)^{2} d x d y=\int_{-1}^{1} \int_{-1}^{1}\left(\frac{\partial^{2} \sum_{m, n} A_{m n} u_{m}(x) u_{n}(y)}{\partial x^{2}}\right)^{2} d x d y \\
=\sum_{m, n} \sum_{p, q} A_{m n} A_{p q} \underbrace{\int_{-1}^{1} \int_{-1}^{1} \frac{\partial^{2} u_{m}(x)}{\partial x^{2}} u_{n}(y) \frac{\partial^{2} u_{p}(x)}{\partial x^{2}} u_{q}(y) d x d y}_{c_{m n p q}^{1}:=}
\end{array}
$$

Since $u_{n}$ is known, it suffices to evaluate the integrals numerically to obtain the coefficients $c_{m n p q}^{1}$. Similarly, one can also evaluate all the other terms in (5.8) to

\footnotetext{
${ }^{14}$ Ritz: "Sämtliche Eigentöne der Platte lassen sich bis auf einige Prozent darstellen durch die Formeln...."

${ }^{15}$ Ritz: "Es liegt nahe, als Masstab des Gesamtfehlers die Abweichung der potentiellen Energie von ihrem exakten Wert beim wirklichen Vorgang zu wählen."
} 
obtain

$$
\begin{aligned}
\int_{-1}^{1} \int_{-1}^{1}\left(\frac{\partial^{2} w_{s}}{\partial y^{2}}\right)^{2} d x d y & =\sum_{m, n} \sum_{p, q} A_{m n} A_{p q} c_{m n p q}^{2} \\
\int_{-1}^{1} \int_{-1}^{1} 2 \mu \frac{\partial^{2} w_{s}}{\partial x^{2}} \frac{\partial^{2} w_{s}}{\partial y^{2}} d x d y & =\sum_{m, n} \sum_{p, q} A_{m n} A_{p q} c_{m n p q}^{3} \\
\int_{-1}^{1} \int_{-1}^{1}(1-\mu)\left(\frac{\partial^{2} w_{s}}{\partial x \partial y}\right)^{2} d x d y & =\sum_{m, n} \sum_{p, q} A_{m n} A_{p q} c_{m n p q}^{4} \\
\int_{-1}^{1} \int_{-1}^{1} w_{s}^{2} d x d y & =\sum_{m, n} A_{m n}^{2} \quad \text { by orthogonality }
\end{aligned}
$$

where all the coefficients $c_{m n p q}^{2}, c_{m n p q}^{3}$, and $c_{m n p q}^{4}$ are defined by concrete integrals, as in (5.10). Using a Lagrange multiplier $\lambda$, we now need to minimize

$$
J\left(w_{s}\right)-\lambda\left(U\left(w_{s}\right)-C\right) \longrightarrow \min ,
$$

which is equivalent to minimizing the finite-dimensional problem

$$
J_{s}(\boldsymbol{a}):=\boldsymbol{a}^{T} \widetilde{K} \boldsymbol{a}-\lambda\left(\boldsymbol{a}^{T} \boldsymbol{a}-C\right) \longrightarrow \min
$$

with respect to $\boldsymbol{a}$, where we define the vector

$$
\boldsymbol{a}:=\left[A_{00}, A_{01}, A_{10}, \ldots\right]
$$

and the matrix

$$
\widetilde{K}:=\left[\begin{array}{cccc}
\alpha_{00}^{00} & \alpha_{01}^{00} & \alpha_{10}^{00} & \ldots \\
\alpha_{00}^{01} & \alpha_{01}^{01} & \alpha_{10}^{01} & \ldots \\
\alpha_{00}^{10} & \alpha_{01}^{10} & \alpha_{10}^{10} & \ldots \\
\vdots & \vdots & \vdots & \ddots
\end{array}\right]
$$

with $\alpha_{m n}^{p q}:=c_{m n p q}^{1}+c_{m n p q}^{2}+c_{m n p q}^{3}+c_{m n p q}^{4}$, using Ritz's original notation.

In order to minimize (5.11), we compute the gradient with respect to $\boldsymbol{a}$ and set it to zero, to obtain with $K:=\frac{1}{2}\left(\widetilde{K}+\widetilde{K}^{T}\right)$

$$
K \boldsymbol{a}=\lambda \boldsymbol{a},
$$

a discrete eigenvalue problem. For each eigenvalue $\lambda^{\ell}$, we get an eigenvector $\boldsymbol{a}^{\ell}=$ $\left[A_{00}^{\ell}, A_{01}^{\ell}, \ldots\right]$ and the corresponding eigenfunction

$$
w_{s}^{\ell}=\sum_{m=0}^{s} \sum_{n=0}^{s} A_{m n}^{\ell} u_{m}(x) u_{n}(y) .
$$

Note the similarity with the underlying continuous eigenvalue problem

$$
\Delta^{2} w=\lambda w
$$

we started with in (5.1).

The infinite partial differential eigenvalue problem has been reduced to the numerical evaluation of several integrals in order to obtain the matrix $K$ and then to the 
solution of an eigenvalue problem using a numerical linear algebra package; both tasks are easy nowadays, if one has a computer available. However, at the time of Ritz, no such tools were available, and Ritz had the daunting tasks of computing approximations of all the integrals by hand and then solving the eigenvalue problem, also by hand. For the integrals, Ritz had to first approximate the one-dimensional basis functions (5.6), which contain in their definition the solution of transcendental equations. Here he noticed that only the first few values of $k_{m}$ need to be computed, ${ }^{16}$ since they quickly become close to $m \pi / 2-\pi / 4$; he then approximated the basis functions for even $m$ by ${ }^{17}$

$$
u_{m}=\cos \left(\frac{m}{2}-\frac{1}{4}\right) \pi x+\frac{(-1)^{\frac{m}{2}} \cosh \left(\frac{m}{2}-\frac{1}{4}\right) \pi x}{\sqrt{2} \cosh \left(\frac{m}{2}-\frac{1}{4}\right) \pi}
$$

(by neglecting $\cos k_{m}$ in the denominator of the defining formula (5.6) compared to $\cosh k_{m}$ ) and by a similar expression for odd $m$. Further approximations were needed throughout ("Begnügt man sich mit vier genauen Ziffern ...," "Mit einer Genauigkeit von mindestens 2 Prozent ...," "Zur Vereinfachung wird man die aus der Symmetrie der Lösung sich ergebenden Beziehungen zwischen den $A_{m n}$ sogleich einführen..."), before Ritz finally transformed the theoretical eigenvalue problem

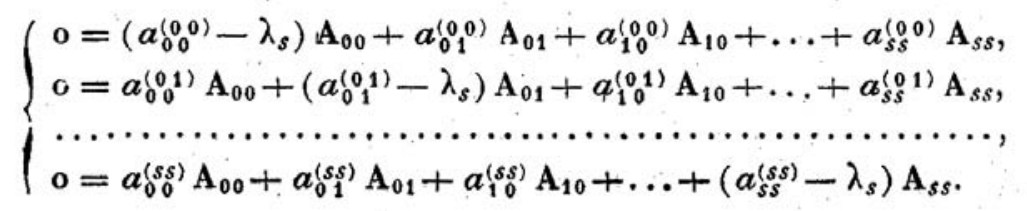

into the concrete numerical one, which contains six coefficients $A_{0}, \ldots, A_{5}$ to be determined for a particular symmetry in the eigenfunction:

$$
\begin{aligned}
u_{m}(y)=v_{m} \text { gesetzt und } \\
\qquad \begin{aligned}
w=\mathbf{A}_{0} u_{1} v_{1}+\mathbf{A}_{1}\left(u_{1} v_{3}+\varphi_{1} u_{3}\right) & +\mathbf{A}_{2} u_{3} v_{3}+\mathbf{A}_{3}\left(u_{1} v_{5}+u_{5} v_{1}\right) \\
& +\mathbf{A}_{4}\left(u_{3} v_{5}+u_{5} v_{3}\right)+\mathbf{A}_{5} u_{5} v_{5} .
\end{aligned}
\end{aligned}
$$

\section{Das System (53) wird hier}

$$
\text { (54) }\left\{\begin{array}{l}
0=(13,95-\lambda) \mathbf{A}_{0}-32,08 \mathbf{A}_{1}+18,60 \mathbf{A}_{2}+32,08 \mathbf{A}_{3}-37,20 \mathbf{A}_{4}+18,60 \mathbf{A}_{5}, \\
o=-16,04 \mathbf{A}_{0}+(41 \mathrm{r}, 8-\lambda) \mathbf{A}_{1}-120,0 \mathbf{A}_{2}-133,6 \mathbf{A}_{3}+166,8 \mathbf{A}_{4}+140 \mathbf{A}_{5}, \\
0=+18,60 \mathbf{A}_{0}-240,0 \mathbf{A}_{1}+(1686-\lambda) \mathbf{A}_{2}-218,0 \mathbf{A}_{3}-1134 \mathbf{A}_{4}+330 \mathbf{A}_{5}, \\
o=+16,04 \mathbf{A}_{0}-133,6 \mathbf{A}_{1}+109,0 \mathbf{A}_{2}+(2945-\lambda) \mathbf{A}_{3}-424 \mathbf{A}_{4}+179 \mathbf{A}_{5}, \\
0=-18,6 \mathbf{A}_{0}+166,8 \mathbf{A}_{1}-567 \mathbf{A}_{2}-424 \mathbf{A}_{3}+(6303-\lambda) \mathbf{A}_{4}-1437 \mathbf{A}_{5}, \\
0=+18,6 \mathbf{A}_{0}+280 \mathbf{A}_{1}-330 \mathbf{A}_{2}+358 \mathbf{A}_{3}-2874 \mathbf{A}_{4}+(13674-\lambda) \mathbf{A}_{5} .
\end{array}\right.
$$

Nowadays, the symbolic calculator Maple can easily perform all these operations! We first define the solution of the transcendental functions defining $k_{m}$ in (5.6) using the command

\footnotetext{
${ }^{16}$ Because $\tanh k_{m}$ approaches 1 very rapidly; Ritz: "Die Wurzeln von $\tan k_{m}+\tanh k_{m}=0$ unterscheiden sich nur wenig von $m \pi / 2-\pi / 4 . "$

${ }^{17}$ Ritz: "Für $m>2$ ist auf vier Stellen genau für gerade $m$."
} 


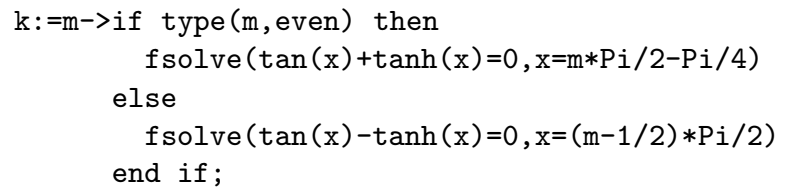

With $k_{m}$ available, we can now define the one-dimensional eigenfunctions $u_{m}$ used by Ritz to construct his coordinate functions, using the Maple command

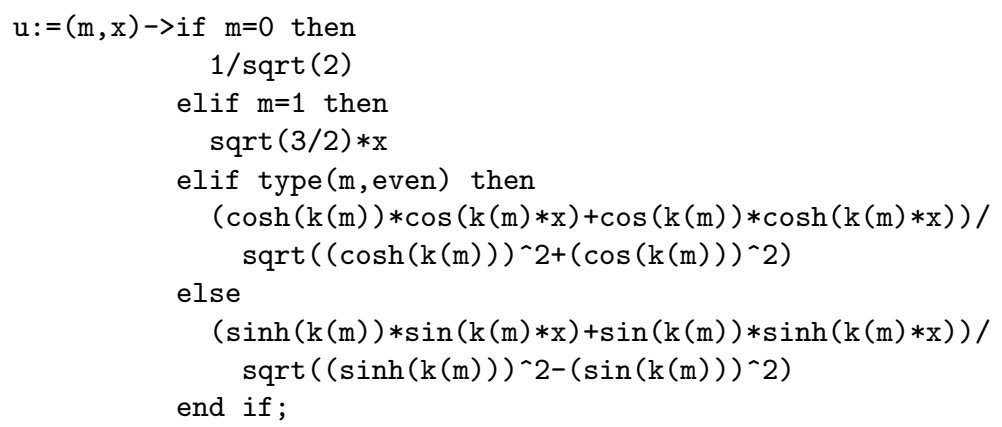

We now simply have to evaluate numerically the integrals in order to obtain the matrix entries:

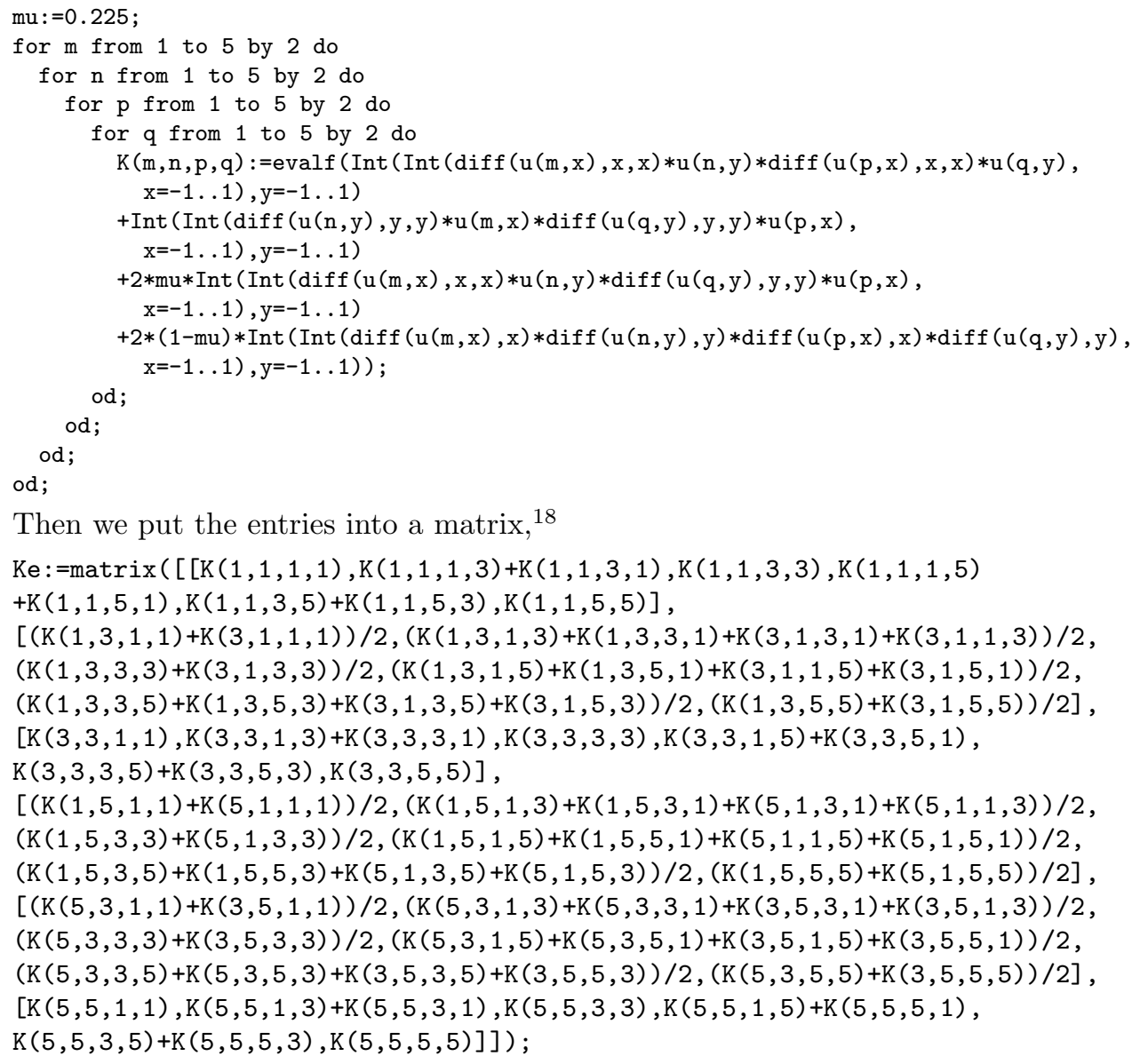

${ }^{18}$ The particular combinations are due to the symmetries Ritz used. 


$$
\begin{aligned}
& 0=(13,95-\lambda) A_{0}-32,08 A_{1}+18,60 A_{2}+32,08 A_{3}-37,20 A_{4}+18,60 A_{8} \\
& 0=-16,04 A_{0}+(411,8-\lambda) A_{1}-120,0 A_{2}-133,6 A_{3}+166,8 A_{4}+140 A_{5} \\
& 0=+18,60 A_{0}-240,0 A_{1}+(1686-\lambda) A_{2}-218,0 A_{3}-1134 A_{4}+330 A_{5} \text {, } \\
& 0=+16,04 A_{0}-133,6 A_{1}+109,0 A_{2}+(2945-\lambda) A_{3}-424 A_{4}+179 A_{5}, \\
& 0=-18,6 \mathbf{A}_{0}+166,8 \mathbf{A}_{1}-52967 \mathbf{A}_{2}-\mathbf{4 2 4} \mathbf{A}_{\mathbf{3}}+(6303-\lambda) \mathbf{A}_{\mathbf{4}}-1437 \mathbf{A}_{5} \text {, } \\
& 0=+18,6 \mathbf{A}_{0}+280 \mathbf{A}_{1}-330 \mathbf{A}_{2}+358 \mathbf{A}_{3}-2874 \mathbf{A}_{4}+(\mathbf{r} 3674-\lambda) \mathbf{A}_{5} \text {. }
\end{aligned}
$$

Fig. 5.3 High accuracy of the results of Ritz.

This leads to the matrix

$\left[\begin{array}{rrrrrr}13.95000000 & -32.21614500 & 18.60000000 & 32.21614504 & -37.20000000 & 18.60000002 \\ -16.10807250 & 406.1196695 & -119.9256010 & -133.5499734 & 172.0806028 & -83.55402336 \\ 18.60000000 & -239.8512019 & 1684.464298 & 217.9828187 & -1136.623991 & 329.5350388 \\ 16.10807252 & -133.5499735 & 108.9914093 & 2945.466708 & -427.1327599 & 179.2413502 \\ -18.60000000 & 172.0806029 & -568.3119956 & -427.1327599 & 6325.441344 & -1441.531357 \\ 18.60000002 & -167.1080467 & 329.5350388 & 358.4827005 & -2883.062714 & 13672.20612\end{array}\right]$.

Comparing this result, computed accurately to about ten significant figures in Maple, with the results obtained by Ritz, who had to approximate not only the roots of the transcendental functions and the functions themselves, but also intermediate results during the computation, we are stunned by the accuracy of Ritz's results: we show in Figure 5.3 the original results of Ritz, highlighting in red the digits which would need to be modified if Ritz had performed his computations to 10 digits accuracy, but with his approximations used for the functions, and in green the digits which would need to be further modified if no approximations to the functions had been made. We can see two likely misprints, the sign of the coefficient $A_{3}$ in the third equation and the sign of the coefficient of $A_{2}$ in the last equation, and maybe one real error, the coefficients in front of $A_{5}$ in the second equation and $A_{1}$ in the last equation; in this case, one should be the double of the other, and both are consistently incorrect by a large margin.

Once Ritz had obtained the discrete eigenvalue problem, he still needed to solve it in order to obtain eigenvalues and eigenvectors, which then allowed him to reconstruct the vibrational modes of the plate using the coordinate functions. At his time, there were no numerical methods available to compute eigenvalues and eigenvectors of a matrix, but again he proved to be far ahead of his time: instead of trying to compute the eigenvalues using the characteristic polynomial, a disastrous approach as we know today for numerical purposes, he invented an iterative method, an approach which has now become standard for both eigenvalue problems and linear systems, and for which very powerful methods are available today. Ritz first fixed one component of the eigenvector, namely, $A_{0}=1$, and took as an approximation to the eigenvalue the first diagonal entry. Then the remaining last five equations were used to determine an approximation to the other components $A_{j}$ of the eigenvector ( "... setzen wir $A_{0}=1$, und in erster Annäherung $\lambda_{0}=13.95$. Dann ergeben die fünf letzten Gleichungen die übrigen $A_{i}$ "). But again, solving this linear system of five equations is too much work by hand, so Ritz proposed to just invert the diagonal of the matrix, in what we would today call a Jacobi step ("Wir berechnen für die $A_{i}$ eine erste Approximation, indem wir alle Glieder rechts vernachlässigen neben den Diagonalgliedern ..."). Having 
this approximation for the eigenvector, one can now compute a correction to the eigenvalue using the first equation, and, according to Ritz, one or two successive iterations suffice in order to obtain about four digits of accuracy ("Ein oder zwei sukzessive Korrektionen genügen meist, um die vierte Stelle bis auf wenige Einheiten festzustellen"). It is worthwhile to write this algorithm in today's notation: solving the eigenvalue problem

$$
K \boldsymbol{a}=\lambda \boldsymbol{a}
$$

for $\boldsymbol{a}:=\left(a_{0}, a_{1}, \ldots, a_{n}\right)$ and $\lambda$ is equivalent to solving the nonlinear system of equations

$$
\boldsymbol{f}\left(\lambda, a_{1}, \ldots, a_{n}\right):=K \boldsymbol{a}-\lambda \boldsymbol{a}=0,
$$

where we have fixed, like Ritz, one component of the eigenvector, $a_{0}:=1$. Ritz's algorithm now starts with $\lambda^{0}=13.95$ and $\left(a_{1}^{0}, \ldots, a_{n}^{0}\right)=\mathbf{0}$, and computes for iteration index $k=0,1, \ldots$

$$
f_{j}\left(\lambda^{k}, a_{1}^{k}, \ldots, a_{j-1}^{k}, a_{j}^{k+1}, a_{j+1}^{k}, \ldots, a_{n}^{k}\right)=0, \quad j=1,2, \ldots, n,
$$

and then solves for a new approximation of the eigenvalue $\lambda^{k+1}$

$$
f_{0}\left(\lambda^{k+1}, a_{1}^{k+1}, \ldots, a_{n}^{k+1}\right)=0 .
$$

Note that in each step of the algorithm, only a scalar linear equation needs to be solved. Implementing this method in MATLAB gives the following short program:

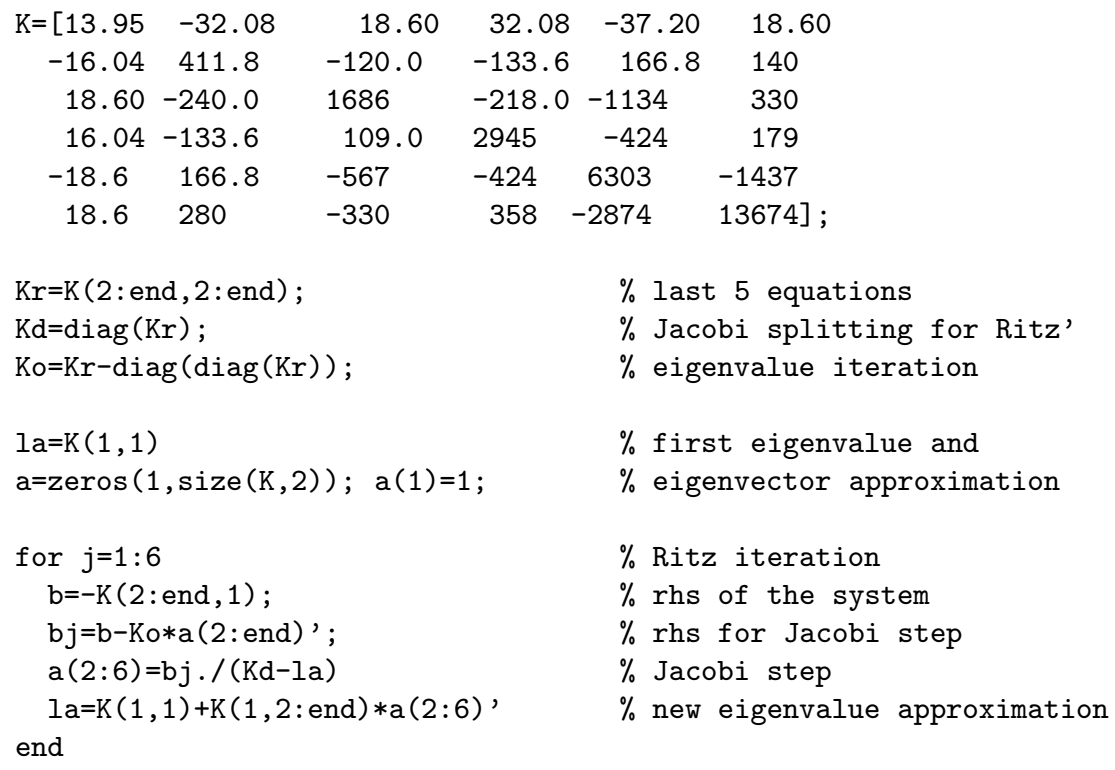

whose output is 


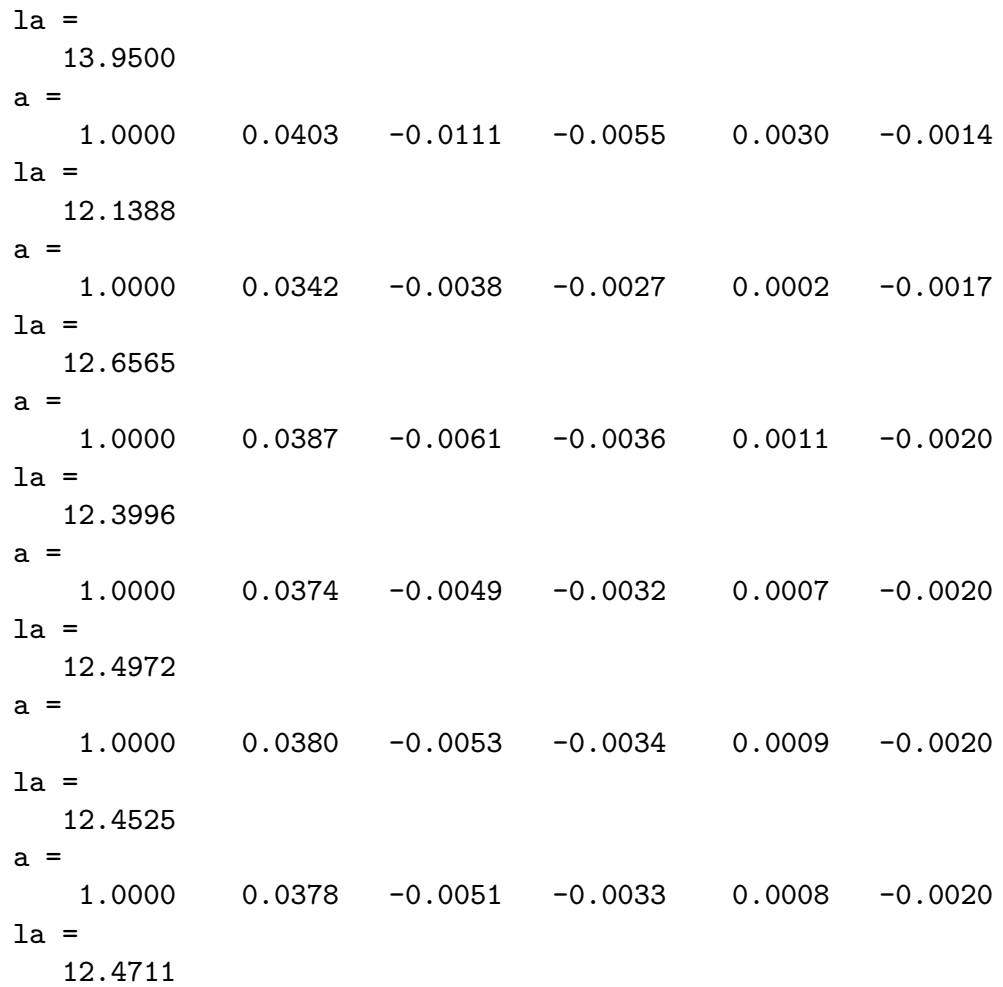

We see that the dominant eigenvector component is the first one, corresponding to the diagonal element, and the eigenvalue indeed seems to converge. In order to obtain the exact eigenvalue of Ritz's matrix, we can use the MATLAB commands

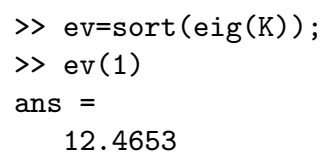

which first computes all eigenvalues, sorts them, and then shows the first one. We see that about four iterations are needed in this case in order to determine the first three digits. It is also interesting to check whether the approximations chosen by Ritz have a significant influence on the eigenvalues. We therefore computed the eigenvalues of Ritz's matrix, the matrix obtained when computing exactly using Ritz's approximations of the quantities in the matrix, and those of the exact matrix. We obtain for the eigenvalues

$\begin{array}{rrr}12.47 & 12.49 & 12.49 \\ 379.85 & 379.14 & 379.34 \\ 1579.79 & 1556.84 & 1559.28 \\ 2887.06 & 2899.82 & 2899.93 \\ 5969.67 & 5957.80 & 5961.32 \\ 14204.92 & 14233.73 & 14235.30\end{array}$

which shows that even with the small error in Ritz's computation in the elements, the approximation has little influence on the final result.

Having obtained these numerical results, all by hand calculations, Ritz went on to compare his results to the physical experiments performed by Chladni. We show in Figure 5.4 the results for the first type of symmetry Ritz computed. We see that in case II, there is excellent agreement between the theoretical and experimental 
A. Lösungen, die in $x$ und $y$ ungerade und symmetrisch sind.

I. Grundton. $\lambda=12,4^{3}-18,0 \hat{\jmath} \mu$.

$w=\mathrm{u}_{1} \mathrm{v}_{1}+0,0394\left(u_{1} v_{3}+v_{1} u_{3}\right)$

$-0,00\left\{0 u_{3} v_{3}-0,003 \dot{4}\left(u_{1} v_{6}+u_{6} v_{1}\right)\right.$

$+0,0011\left(u_{3} v_{6}+u_{5} v_{3}\right)-0,0019 u_{5} v_{5}$.

Fig. 1.

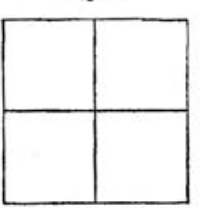

II. $\lambda=378-57 \hat{\delta} \underline{\mu}$.

$$
\begin{aligned}
w= & -0,075 u_{1} v_{1}+\left(\mathbf{u}_{1} \mathbf{v}_{3}+u_{3} v_{1}\right) \\
& +0,173 u_{3} v_{3}+0,045\left(u_{1} v_{5}+u_{5} v_{1}\right) \\
& -0,015\left(u_{3} v_{5}+u_{5} v_{3}\right)-0,029 u_{5} v_{5} .
\end{aligned}
$$

Es ist

$\begin{array}{rccccccl}y \text { beob. : } & 0,530 & 0,578 & 0,630 & 0,690 & 0,752 & 0,819 & 0,893 \\ x \text { beob. : } & 0,9375 & 0,8750 & 0,812_{5} & 0,7500 & 0,68-5 & 0,6250 & 0,5625 \\ x \text { ber, }-x \text { beob. : } & -0,003 & -0,002 & 0,000 & -0,001 & -0,000_{5} & 0,000 & 0,000\end{array}$

III. $\lambda=1554$.

$w=0,009 u_{1} v_{1}-0,075\left(u_{1} v_{3}+v_{1} u_{3}\right)$

$+u_{3} v_{3}-0,057\left(u_{1} v_{5}+u_{5} v_{1}\right)$

$+0,121\left(u_{3} v_{5}+u_{6} v_{3}\right)-0,007 u_{6} v_{5}$.

Messungen fehlen.

R.

IV. $\lambda=2945$.

$w=u_{1} v_{8}+u_{5} v_{1}$

Diese Figur fehlt bei Chladni.

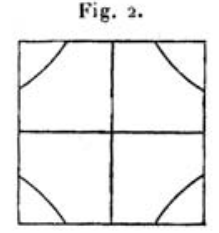

Fig. 3 .

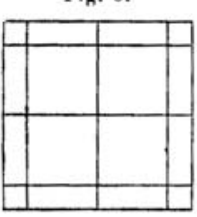

20

Fig. 4.

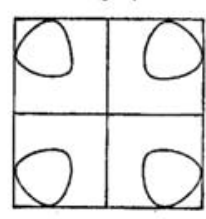

Fig. 5.

v. $\lambda=6303$.

$$
w=u_{3} v_{5}+u_{5} v_{3} .
$$

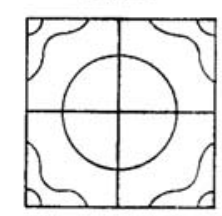

Fig. 6.

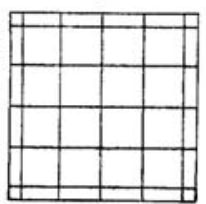

$\overline{\text { Fig. } 5.4 \text { Comparison done by Ritz of his computational results with physical experiments, for the }}$ first few cases. 
Tabelle der Tonhöhen $(\mu=0,225)$.

\begin{tabular}{|c|c|c|c|c|c|c|c|}
\hline HAUPTGLIEDER & $\lambda$ & BER. & BEOB. & HAUPTGLIEDER & $\lambda$ & BER. & BE0B. \\
\hline$u_{1} v_{1}$ & 12,43 & $G^{\star}$ & G & $u_{3} v_{4} \pm u_{4} v_{3}$ & 3240 & $g_{3}+$ & $\mathrm{fis}_{3}$ \\
\hline$u_{0} v_{2}-v_{0} u_{2}$ & 26,40 & $d^{\star}$ & $d$ & $u_{5} v_{2} \pm u_{2} v_{5}$ & $39^{27}$ & $a_{3}+$ & $\mathrm{gis}_{3}+$ \\
\hline$u_{0} v_{2}+v_{0} u_{2}$ & $35,7^{3}$ & $e^{\star}$ & $e$ & $u_{4} v_{4}$ & 5480 & $\mathrm{ais}_{3}+$ & $a i s_{3}$ \\
\hline$u_{1} v_{2} \pm u_{2} v_{1}$ & 80,8 & $h^{\star}$ & $h$ & $u_{0} v_{6}-u_{6} v_{0}$ & 5500 & $c_{4}-$ & $-\left({ }^{2}\right)$ \\
\hline$u_{0} v_{3} \pm u_{3} v_{0}$ & $237, x$ & gis $_{1}{ }^{*}+$ & $g i s_{1}+$ & $u_{3} v_{5}-u_{5} v_{3}$ & 5570 & $c_{4}-$ & $a i_{3}-$ \\
\hline$u_{1} v_{i}$ & 266,0 & ais $_{1}{ }^{*}-$ & $\operatorname{ais}_{1}{ }^{*}-$ & $u_{0} v_{6}+u_{6} v_{0}$ & $564^{\circ}$ & $c_{4}-$ & $-\left({ }^{2}\right)$ \\
\hline$u_{1} v_{3}-u_{3} \nu_{1}$ & $3 \mathrm{r} 6, \mathrm{x}$ & $h_{1}{ }^{\star}$ & $h_{1}$ & $u_{1} v_{6} \pm v_{1} u_{6}$ & 6036 & $c_{4}+$ & $c_{4}-$ \\
\hline$u_{1} v_{3}+u_{3} v_{1}$ & 378 & $c i s_{2}{ }^{\star}$ & $\mathrm{cis}_{2}$ & $u_{3} v_{5}+u_{5} v_{3}$ & $63 \mathrm{o} 3$ & $\mathrm{cis}_{4}$ & $c_{4}-$ \\
\hline$u_{2} v_{3} \pm u_{3} v_{2}$ & 746 & $\mathrm{fis}_{2}{ }^{*}+$ & $\mathrm{fis}_{2}$ & $u_{2} v_{6}-u_{6} v_{2}$ & $7^{310}$ & $d_{4}+$ & $c i s_{4}+$ \\
\hline$u_{0} v_{4}-v_{0} u_{4}$ & 886 & $g i s_{2}$ & $g i s_{2}$ & $u_{2} v_{6}+u_{6} v_{2}$ & 7840 & $d i s_{4}-$ & $d_{4}-$ \\
\hline$u_{0} v_{4}+v_{0} u_{4}$ & 941 & $g i s_{2}+$. & $g i_{2}+$ & $u_{5} v_{4} \pm u_{4} v_{5}$ & 9030 & $e_{4}$ & $d i s_{4}$ \\
\hline$u_{1} v_{4} \pm u_{4} v_{1}$ & I 31 & $a i s_{2}$ & $a^{a i s_{2}}-$ & $u_{6} v_{3} \pm u_{3} v_{6}$ & ro380 & $f_{4}$ & $e_{4}$ \\
\hline$u_{3} v_{3}$ & 1554 & $c_{3}+$ & $c_{3}$ & $u_{5} v_{5}$ & $\mathbf{x} 3670$ & $g_{4}+$ & fis $_{4}+$ \\
\hline$u_{2} v_{4}-u_{4} v_{2}$ & 1702 & $d_{3}-$ & $c i s_{3}$ & $u_{6} v_{4}-u_{4} v_{6}$ & I 3840 & $g_{4}+$ & $g_{4}+$ \\
\hline$u_{2} v_{4}+u_{4} v_{3}$ & 2020 & $d i s_{3}$ & $d_{3}$ & $u_{6} v_{4}+u_{4} v_{6}$ & $15 \times 20$ & $g^{2 i s_{4}+}$ & $g_{4}+$ \\
\hline$u_{0} v_{5} \pm v_{0} u_{5}$ & 2500 & $f_{3}-$ & $f_{3}-$ & $u_{6} v_{5} \pm u_{5} v_{6}$ & 20400 & $h_{i}$. & $\operatorname{ais}_{4}-$ \\
\hline$\underline{u}_{1} v_{5}-v_{1} u_{5}$ & $27 \times 3$ & $\mathrm{fis}_{3}$ & $\mathrm{fis}_{3}-$ & $u_{6} v_{6}$ & 28740 & $d_{5}$ & $-\left({ }^{2}\right)$ \\
\hline$u_{1} v_{5}+v_{1} u_{5}$ & 2945 & $\mathrm{fis}_{3}+$ & fis $_{3}\left({ }^{1}\right)$ & & & & \\
\hline
\end{tabular}

Fig. 5.5 Table of frequencies obtained by Ritz for the pitch of the sound of the plate, compared to the results measured by Chladni.

results (trivially in case I). In case III, there were no measurements available. Case VI was not obtained by Chladni, and we see in Figure 5.4 that fairly complicated patterns arise for the later cases. Ritz also used his method to estimate the pitch of the sound and compared his result with the pitch measured by Chladni. Due to the enormous demand made by the computations, however, Ritz only used his full method of approximation with several terms in the expansion for the first 9 notes, marked with a star in the original table given in Figure 5.5. For the remaining notes, he only used the first term in the expansion. It is remarkable how well Ritz's results agree with the physical experiments of Chladni!

5.3. First Reactions to Ritz's Work in Western Europe. In Göttingen, where Ritz spent the last years of his life and which was then the principal center of mathematical research, the importance of Ritz's invention was not immediately accepted. None of the many doctoral and habilitation theses written under Hilbert in these years on the Dirichlet Principle makes any reference to Ritz's work. The only exception is the paper by König [27], who just says that Ritz had simplified somewhere some lines of Hilbert's proof. Ten years later, we read in a footnote in the famous book of Hurwitz and Courant [24] (see Figure 5.6) the following:

The actual, for this proof of existence unimportant [italics by us], construction of minimal sequences causes no problems in principle. For example if $G$ is a finite domain, bounded by curves $C$ without multiple points, we 
1) Die wirkliche, für den blofsen Existenzbeweis unerhebliche Konstruktion solcher Minimalfolgen macht keinerlei prinzipielle Schwierigkeiten. Jst z. B. $G$ ein ganz im Endlichen gelegener Bereich, begrenzt von Kurven $C$ ohne mehrfache Punkte, so denken wir uns denselben mit einem noch von dem Index $j$ abhängigen Dreiecksnetz $T_{j}$ überdeckt, dessen Maschen mit wachsendem $j$ immer enger werden. Wir betrachten nun nur solche Funktionen $\varphi$ bzw. $\boldsymbol{\Phi}=\varphi-S$, wo die Differenz $\varphi-\frac{x}{x^{2}+y^{2}}$ in jedem Dreieck von $T_{j}$ eine lineare Funktion wird. Unter $\Phi_{j}$ verstehen wir diejenige unter den so entstehenden zu $T_{j}$ konstruierten Funktionen, für welche $D[\Phi]$ einen möglichst kleinen Wert erhält. Diese Forderung $D[\Phi]=$ Min. ist jetzt ein Problem eines Minimums einer Funktion von einer endlichen Anzahl von Variablen, nämlich des Integrals, aufgefafit in seiner Abbängigkeit von den Werten von $\varphi$ in den Eckpunkten der Dreieckseinteilung; dieses Problem ist gewifs lösbar, und zwar, wie leicht ersichtlich, mittels linearer Gleichungen. Daf3 die so entstehenden Funktionen $\Phi_{j}$ wirklich eine Minimalfolge bilden, folgt sofort aus der unschwer beweisbaren Tatsache, daß̧ man jede zulässige Funktion $\Phi$ und deren Dirichletsches Integral mit Hilfe unserer Konstruktion bei hinreichend großem $j$ beliebig genau approximieren kann.

Fig. 5.6 Footnote in the first edition of the book by Hurwitz and Courant [24].

imagine that $G$ is covered by a triangular grid $T_{j}$, whose triangles become smaller when $j$ increases. We consider now only functions $\varphi$ or $\phi=\varphi-S$, where the difference $\varphi-\frac{x}{x^{2}+y^{2}}$ in each Triangle of $T_{j}$ is a linear function. The function $\phi_{j}$ is then the function associated with $T_{j}$, such that $D[\phi]$ has as small a value as possible. The requirement that $D[\phi]=$ Min is now a problem of minimization with a finite number of variables, namely the integrals, understood in dependence of the values of $\varphi$ in the nodes of the triangular mesh; this problem can certainly be solved, as one can easily see, with linear equations. The fact that the functions so created form a minimization sequence follows immediately from the easy to prove fact that one can approximate each admissible function $\phi$ and the corresponding Dirichlet integral with the help of our construction with sufficiently large $j$ to arbitrary accuracy.

We see that Courant had little interest in Ritz's method and did not mention Ritz at all. His low esteem for practical questions at that time even led him to remove this footnote from the second edition (1925) of the book. He removed, at the same time, the historically first description of what later became one of the most important tools for scientific computation, the finite element method. We will come back to this in section 7 .

Even more sad was the fact that the famous, and by then old, Lord Rayleigh published an article [42] in which he accused Ritz of plagiarism and claimed that all of Ritz's ideas were already present in his own prior work. This led to the name of "Rayleigh-Ritz" for this method, accepted by many scientists. A very careful study of all the original papers carried out by Leissa [30] made it clear that this claim is not at all justified.

6. Immediate Use of Ritz's Method in Russia. Unlike in Western Europe, Ritz's method was immediately put to use in Russia, in order to solve hard engineering problems. 
Fig. 6.I "Shveitsarskogo uchenogo Val'tera Rittsa," as Timoshenko refers to the inventor of the method in his original publication in Russian.

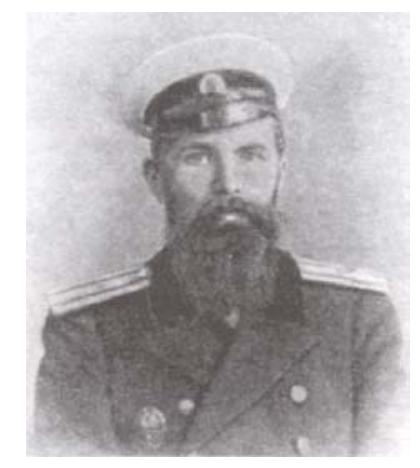

СТРОИТЕЛЬНАЯ МЕХАНИКА КОРАБЛЯ [] [РАЗДЕЛЫ, ОТНОСЯЩИЕСЯ К ТЕОРИИ ПЛАСТИН]

Structural Mechanics of Shipbuilding

[Part concerning the theory of shells]

Fig. 6.2 Ivan Bubnov (1872-1919) and the title of his monumental manual for the construction of ships.

6.I. Timoshenko. S. P. Timoshenko (1878-1972), a professor then working at the Politekhnicheskyi Institut of Kiev, later in St. Petersburg, and still later at Stanford, was the first to realize the importance of Ritz's invention for applications [45]:

Nous ne nous arrêterons plus sur le côté mathématique de cette question: un ouvrage remarquable du savant suisse, M. Walter Ritz, a été consacré à ce sujet. En ramenant l'intégration des équations à la recherche des intégrales, M. W. Ritz a montré que pour une classe très vaste de problèmes, en augmentant le nombre de paramètres $a_{1}, a_{2}, a_{3}, \ldots$, on arrive à la solution exacte du problème. Pour le cycle de problèmes dont nous nous occuperons dans la suite, il n'existe pas de pareille démonstration, mais l'application de la méthode approximative aux problèmes pour lesquels on possède déjà des solutions exactes, montre que la méthode donne de très bons résultats et pratiquement on n'a pas besoin de chercher plus de deux approximations ${ }^{19}$

We also show the "shveitsarskogo uchenogo Val'tera Rittsa," of this quote in the original Russian publication in Figure 6.1. Timoshenko then showed how many interesting problems can immediately be solved approximately, using Ritz's method.

6.2. Bubnov. Ivan Bubnov (1872-1919; see Figure 6.2), was a structural engineer specialized in the construction of ships, in particular, submarines. Like Timoshenko, he was also working at the Polytechnical Institute of St. Petersburg, and he needed to calculate the behavior of shells for the construction of submarines. Fascinated by

\footnotetext{
19 "We will not address the mathematical aspects of this method: a remarkable publication of a Swiss scientist, Mr. Walter Ritz, was dedicated to this subject. Transforming the problem of integrating the equations into a problem of evaluating integrals, Mr. W. Ritz has shown for a large class of problems, that by increasing the parameters $a_{1}, a_{2}, a_{3}, \ldots$, one can find the exact solution of the problem. For the problems we are interested in here, however, such a proof does not exist, but the application of the method to problems for which we know an exact solution shows that the method gives very good results and in practice one does not need to compute more than two approximations."
} 


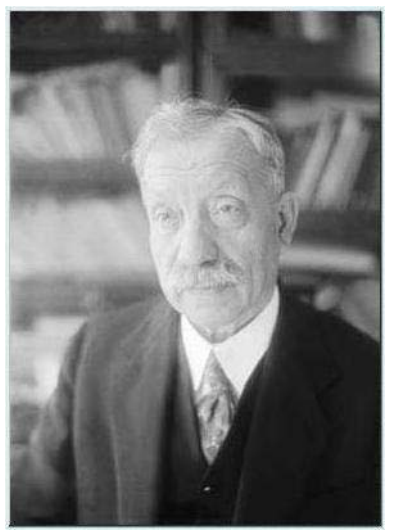

CTEPЖНИ I IJАСТНHЕК

РЯДЫ В HEROTOPЫX BOMPOCAX УПРУ СOTO PABHOBECH СТЕРЖНЕЙ И ДЛАСТКНОК*

(1lempozas, 1915)

Beams and Plates

Using Series for some problems in the elastic equilibrium of rods and plates

(Petrograd, 1915)

Fig. 6.3 Boris Grigor'evich Galerkin and the famous paper which is now quoted in the literature as containing the invention of the "Galerkin." method.

the work of Timoshenko (Bubnov does not cite the work of Ritz directly), especially the simplicity of the approach and the accuracy of the results, he developed an entire battery of problems with approximate solutions in his manual on ship building [4]. A main contribution of Bubnov to the development of the finite element method is that he realized in [3], after studying the Zhuranskyi prize-winning work of Timoshenko, that

... extremely simple solutions can also be obtained in the usual way, i.e., without resorting to a consideration of the energy of the system [ ...] we simply substitute the expansion for $w$ in the general differential expression for equilibrium, multiply the expression obtained by $\varphi_{k} d x d y$ and integrate over the entire volume of the body, then we obtain an equation relating the coefficient $a_{k}$ with all others $[\ldots]$ and will be identical to those found by Prof. Timoshenko.

This remark simplified the construction of linear systems for the computation of the coefficients by giving an easy-to-remember recipe. Bubnov also required the coordinate functions to be orthogonal in his remark, without giving a justification. He used, in general, trigonometric functions for $\varphi_{k}$.

6.3. Galerkin. Boris Grigor'evich Galerkin (1871-1945; see Figure 6.3) came from a poor family and had to start working at the age of twelve as a calligrapher. Nevertheless, he managed to study in the Mechanics Department of the St. Petersburg Technological Institute, and then he worked for the Russian Steam-Locomotive Union and the China Far East Railway. He was also interested in politics, and was arrested in 1905 for political activities and put into prison for one and a half years. This completely changed his interests, and it was while in prison that he decided to devote the rest of his life to science. Galerkin went on an extensive scientific trip through Europe in 1909 and visited Switzerland, among other countries. We do not know whether he met Walter Ritz on this trip, but Galerkin makes precise references to both papers of Ritz in his most famous publication [15], which is now usually quoted when referring to the Galerkin method; Galerkin himself called this method the Ritz method; see Figure 6.4. In this paper, Galerkin introduces Ritz's method on the first few pages, and then goes on to show how the method can be used to solve approximately many interesting and difficult problems arising from applications. Galerkin noticed that 
Из приближенных методов решений широкое применение получил в последнее время метод Ритца ${ }^{6,7]}$. Этот метод сводится вкратце к следующему.

\section{Л С T E P A T Y P A}

3. Бубно в И. Г'. Строительная механика ћорабля. Ч. 2, СІб., 1914.

$$
\cdots
$$

8. Hitz $\mathrm{W}$. Uber eine neue Methorle zur Lösung gewisser Vuriationsprobleme der mathematiseken Physik. Journal f. retine $t$. fngewande Mathematik, 1908, Bd. $135,5.1-61$.

7. Ritz W. Theorje der Transversalschwiugunger einer quadralischen Platte mit freien Rändern.- Annalen der Physik, 1969, Bd. 28, N. 4, S. 737-786.

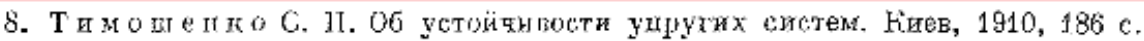

Fig. 6.4 Galerkin himself called the method which today carries his name the "Ritz Method," and he cited all of Ritz's papers, as well as the work by Bubnov and Timoshenko.

the coordinate functions do not need to be orthogonal; one simply gets an additional matrix, which is today called the mass matrix. However, the main contribution of Galerkin in this paper was to realize that one does not even need a minimization principle in order to construct a finite-dimensional system following the recipe given by Bubnov. One can only speculate as to why the method is nowadays generally called the Galerkin method; maybe Galerkin's numerous examples from applications were more appreciated than the theoretical analysis of Ritz. Most readers did not even notice the name of the method in Galerkin's introduction, and went straight to the examples that form the bulk of Galerkin's paper.

7. Late Recognition of Ritz's Work in Western Countries and the Birth of Finite Element Methods. Inspired by Hilbert's ideas, a tremendous number of pure mathematicians applied what became known as direct methods of variational calculus in order to prove various existence theorems. An overview of these developments is given in the paper by Richard Courant [10]. In this paper, Courant gives credit to Walther Ritz for the method of finding the coefficients. ${ }^{20}$

Almost three decades after Ritz's tragic death, Richard Courant became really interested in practical applications and gave an address to the American Mathematics Society on May 3, 1941 [11], which he began with the text shown in Figure 7.1. In this address, Courant greatly praised the work of Ritz:

At first, the theoretical interest in existence proofs dominated, and only much later were practical applications envisaged by two physicists, Lord Rayleigh and Walther Ritz. They independently conceived the idea of utilizing this equivalence for numerical calculation of the solutions, by substituting for the variational problems simpler approximating extremum problems in which but a finite number of parameters need be determined

But only the spectacular success of Walther Ritz and its tragic circumstances caught the general interest. In two publications of 1908 and 1909,

\footnotetext{
20 “... einer vielfach auch praktisch angewandten allgemeinen Methode, welche nach Walther Ritz benannt wird."
} 


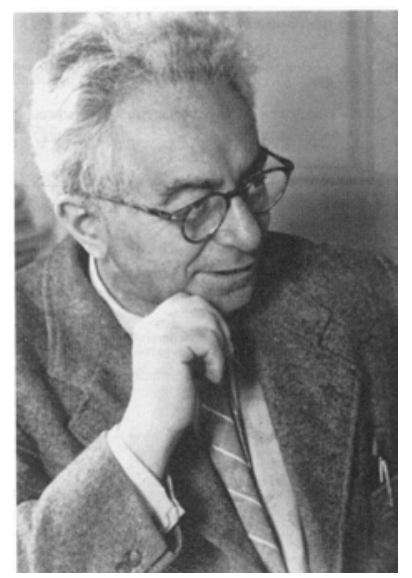

As Henri Poincaré once remarked, "solution of a mathematical problem" is a phrase of indefinite meaning. Pure mathematicians sometimes are satisfied with showing that the nonexistence of a solution implies a logical contradiction, while engineers might consider a numerical result as the only reasonable goal. Such one-sided views seem to reflect human limitations rather than objective values.

Fig. 7.I Richard Courant and the beginning of his address to the American Mathematical Society in 1941, marking a turning point in his appreciation of Ritz's work.

Ritz, conscious of his imminent death from consumption, gave a masterly account of the theory, and at the same time applied his method to the calculation of the nodal lines of vibrating plates, a problem of classical physics that previously had not been satisfactorily treated.

Clearly, the tide had turned, and Ritz's work was now held in high esteem by Courant. In addition, Courant now also realized the importance of the footnote from the first volume of his book with Hurwitz [24]:

However, the difficulty that challenges the inventive skill of the applied mathematician is to find suitable coordinate functions.

Instead of the eigenfunctions used by Ritz as coordinate functions and the trigonometric functions employed by Bubnov and Galerkin, Courant now suggested the use of what are nowadays called hat functions; see Figure 7.2. In two dimensions, the piecewise linear functions Courant had in mind are most easily defined on a triangular mesh, in contrast to the up-to-then dominant finite difference method on a rectangular grid:

Instead of starting with a quadratic or rectangular net we may consider from the outset any polyhedral surfaces with edges over an arbitrarily chosen (preferably triangular) net.

We show a few examples of such hat functions in Figure 7.3. In his address, Courant presented the first finite element calculation that we were able to find, shown in Figure 7.4. Courant chose as a model problem a square domain with a hole (see Figure 7.4 on the left), and wanted to minimize the functional

$$
\iint\left((\nabla u)^{2}+2 u\right) d x d y \longrightarrow \min
$$

with $u=0$ on the outer boundary and $u=c$, an unknown constant, on the inner boundary. He then compared the results obtained for $c$ and the total stiffness

$$
S:=-\iint u d x d y
$$

with different coordinate functions: 
Ritz's choice:

Eigenfunctions of the one-dimensional beam, or polynomials

Bubnov/Galerkin: Use trigonometric functions or polynomials

Courant's choice:

Use hat functions, or polynomials on elements
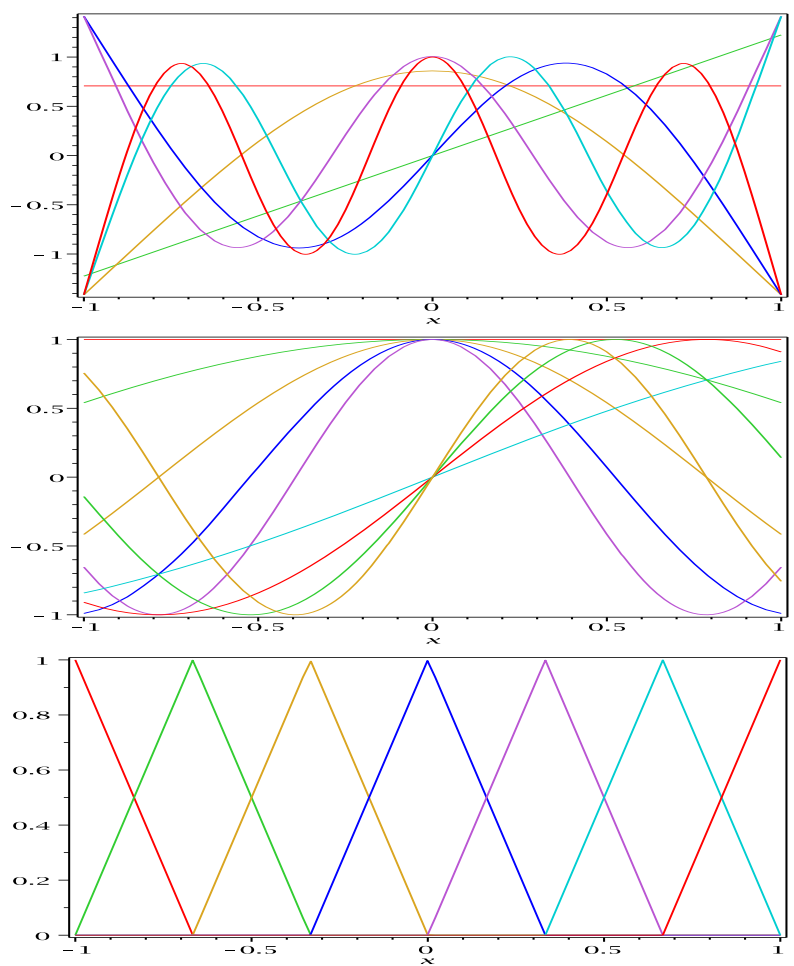

Fig. 7.2 Different choices for the coordinate functions.

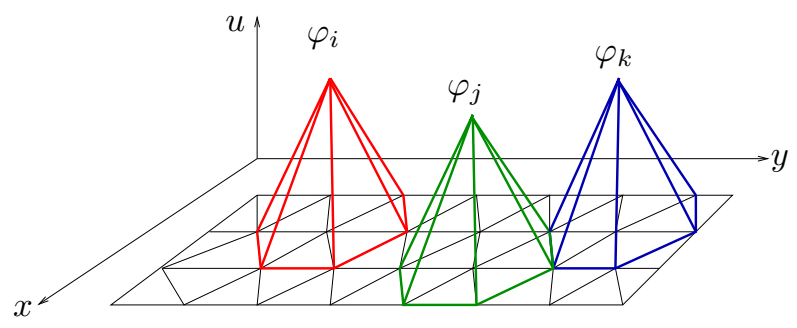

Fig. 7.3 Examples of hat functions in two dimensions.

Polynomials ("with negligible amount of numerical labor"):

$$
\begin{gathered}
\varphi_{1}:=a(1-x), \quad S=0.339, c=-0.11 \\
\varphi_{2}:=a(1-x)\left[1+\alpha\left(x-\frac{3}{4}\right) y\right], \quad S=0.340, c=-0.109 .
\end{gathered}
$$

Finite Elements ("the results, easily obtainable, were"):

Case (a): $S=0.344, c=-0.11$.

Case (b): $S=0.352, c=-0.11$.

Case (c): $\quad S=0.353, c=-0.11$.

Case (d): $S=0.353, c=-0.11$. 


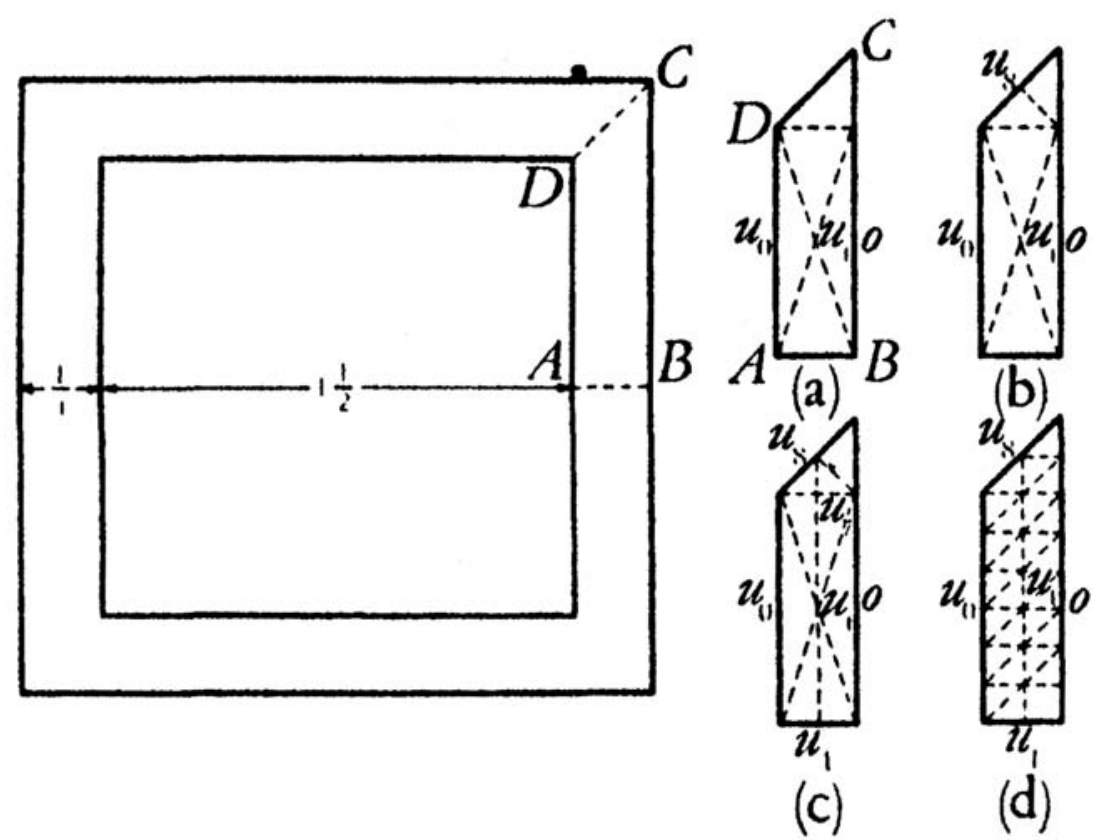

Fig. 7.4 The first finite element computation we were able to find, by Richard Courant.

Courant concludes that "these results show in themselves and by comparison that the generalized method of triangular nets seems to have advantages."

The development of what was to become the finite element method proceeded on many fronts: on the mathematical side, Trefftz [46] proposed in 1926 to use local basis functions in the Ritz method. In Russia, Petrov [34] proposed to use approximation spaces different from the test spaces, which led to the now-called Petrov-Galerkin family of methods. ${ }^{21}$ A little later, Polya [35] gave an interpretation of the finite difference method using piecewise polynomial approximations, and Argyris [1] combined system theory available at that time with variational approximation in a fundamental step toward a true finite element methodology. Tending to the engineering side, Hrennikoff [23] used local approximations in the form of bars, beams, and spring elements in order to treat plane elasticity problems, and McHenry [32] developed his "lattice analogy." Over the same time, Kron developed his tensor analysis of networks using a method of tearing (see $[28,29]$ ), and Levy developed the direct stiffness method for aircraft simulation [31]. The term finite element method was then coined by Ray Clough in [6], who had started to work with Jon Turner from Boeing on structural dynamics, and this work led to the first published description of the finite element method, still without its name, in [47]; see also the historical note by Ray Clough [7].

8. An Application. We now leave the sunny Swiss Alps mentioned at the beginning of this article (see Figure 1.1) and turn to the cold Canadian winter, to illustrate

\footnotetext{
${ }^{21}$ Petrov wrote "Metod Galerkina" for Galerkin's "Metod Ritza." On the other hand, S. L. Sobolev, in the first edition of his textbook The Equations of Mathematical Physics from 1947, dedicated an entire chapter to "Metod Ritza." Kantorvich and Krylov in their book Approximation Methods in Numerical Analysis (Moscow 1952) have a section titled "Metod Ritza i Metod B.G. Galerkina."
} 

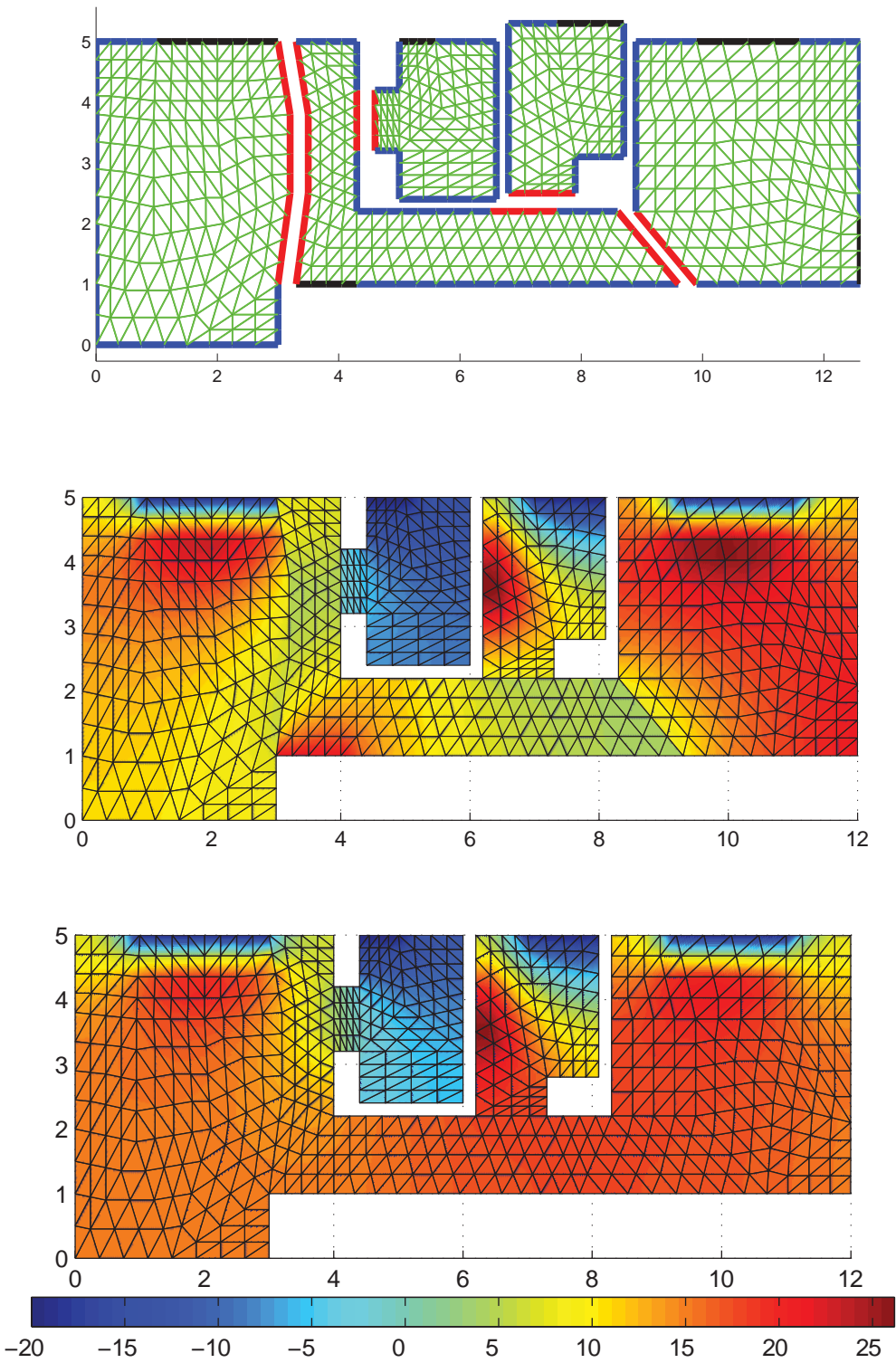

Fig. 8.I Triangulation and decomposition of the apartment in Montreal; in the middle is the first Schwarz iteration, and at the bottom is the converged temperature distribution.

how Ritz's method, as well as Schwarz's method (see (2.10)), are used today in scientific computing. We compute the temperature distribution in a heated, but not well insulated apartment on Durocher Street in Montreal, shown in Figure 8.1. The walls are shown in blue, the windows in black on top, and there are also doors in black at the bottom and on the right-hand side. We assume that the windows are at $-20^{\circ} \mathrm{C}$ and the doors at $15^{\circ} \mathrm{C}$. The steady-state heat equation is

$$
-\Delta u=f \quad \text { in the apartment, }
$$


where the heat source term $f$ is nonzero at the heater locations, which are close to the window for the two big rooms on the left and the right and on the left wall in the third room from the left; there is no heater in the second room from the left.

We use a Schwarz domain decomposition method, in which the apartment is decomposed into separate rooms, as shown by the red partitions in Figure 8.1, and a finite element discretization of the problem with linear triangular finite elements, as shown by the mesh in the figure. The "Grundfunktionen" of the Ritz method are therefore simple linear hat functions. In the middle of Figure 8.1 we show the first iteration of the Schwarz method, where one can clearly see the isolated effect of the heaters and warm doors in each subdomain. At the bottom we show the final result of the simulation, which is now continuous. This result is interesting: one can see that while the heaters in the living room on the left and the bedroom on the right are well placed to block the cold from the windows, the heater on the left wall in the bathroom is not effective to keep the room warm, a fact the occupant strongly felt in winter. Also, the kitchen is not heated and stays cold, except when cooking.

9. Conclusions. We have tried to give as complete a description as possible of the development which led from the variational calculus to Ritz's work and the finite element method. There are other descriptions of these historical developments in the literature; see, for example, the nice article by Oden [33], which also contains the history of the development of the mathematical theory, the review of the Courant element by Babuška [2], the short description by Taylor [43], and the longer study by Leissa [30]. An extensive "glimpse" of the literature of variational calculus can be found at the end of Volume II of Giaquinta and Hildebrandt [18].

9.I. Back to Euler-the Last Surprise. After all these controversies (should the method be called the Rayleigh method? Rayleigh-Ritz? Ritz method? RitzGalerkin? Bubnov-Galerkin? Timoshenko-Bubnov-Galerkin? Galerkin method?), let's have a fresh look at Euler's original work from 1744. We described earlier that Euler published in 1744 the differential equations (1.3) for the variational problem (1.2), and that the standard proof for this equation was found much later. The natural question is thus: how did Euler himself find "his" differential equation for a variational problem? We observe in Caput II of E65 [12] the following procedure:

1. Approx. curve by polygon

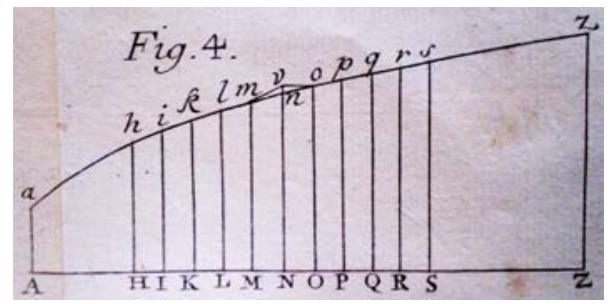

2. Approx. integral by sum

$Z d x+Z^{\prime} d x+Z^{\prime \prime} d x+Z^{\prime \prime} d x+\& c$.

3. Differentiate with resp. to $\nu\left(\boldsymbol{P}+N^{\prime} d x-\boldsymbol{P}^{\prime}\right)$ where $\begin{aligned} & N=\frac{\partial Z}{\partial y}, \\ & P=\frac{\partial Z}{\partial p}\end{aligned}$

4. Set this derivative to zero, apply Euler's method inversely

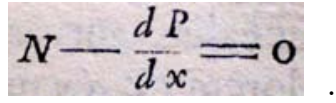

What did Euler do? In step 1 he discretized the curve by a finite-dimensional object, which is precisely from the hat function finite element space applied to the 
one-dimensional case. In step 3 he solved directly the finite-dimensional problem which he had obtained after discretizing the integral in step 2. This direct solution by a discretized finite element approximation was the only thing he could do, before "his" differential equation in step 4 had been found.

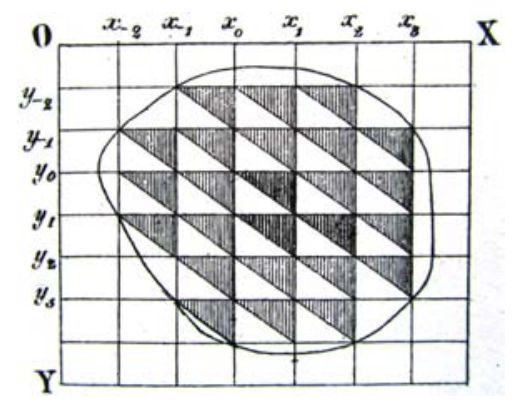

Fig. 9.I The two-dimensional triangular finite element space in Schellbach, 1852, [40].

9.2. Another surprise. The two-dimensional triangular finite element approximations can also be found in the older literature, in the publication of Schellbach [40] from 1852, who proposed to solve many problems of variational calculus in the spirit of Euler. For his treatment of the minimal surface problem in section 30, see Figure 9.1.

Acknowledgment. The authors would like to thank Jean-Claude Pont, the initiator of the centenary conference of Ritz's death in Ritz's hometown of Sion, Switzerland. They also are grateful to Ernst Hairer, Ulrich Langer, Fritz Nagel, and Heinrich Reitberger for many hints, references, and comments, and also to two anonymous referees for reading the manuscript with great care. T. Smirnova and A. Alekseev in Geneva helped them to understand the Russian texts.

They further thank the Bibliothèque de Genève for granting permission to reproduce photographs from the original works under catalogue numbers Ka 337 (Euler E342), Ka 368 (Euler E65), and Ka 434 (Crelle Journal). Figure 3.1 (J. f. Math. und Physik) has been reprinted with permission from Bibliothèque Georges de Rham in Geneva. All images from Russian journals are from the Library of the Steklov Mathematical Institute and were sent to the authors by Armen Glebovich Sergeev, to whom they are extremely grateful.

\section{REFERENCES}

[1] J. ARgYris, Energy theorems and structural analysis, Aircraft Engrg., 26 (1954), pp. 347-356, 383-387, 394.

[2] I. BABuŠKA, Courant element: Before and after, in Finite Element Methods: Fifty Years of the Courant element, M. Kř́žek, P. Neittaanmäki, and R. Stenberg, eds., Marcel Dekker, New York, 1994, pp. 37-51.

[3] I. G. Bubnov, Report on the works of Professor Timoshenko which were awarded the Zhuranskyi Prize, Symposium of the Institute of Communication Engineers, 81 (1913), All Union Special Planning Office (SPB) (in Russian).

[4] I. G. Bubnov, Structural Mechanics of Shipbuilding, 1914 (in Russian).

[5] E. F. F. Chladni, Entdeckungen über die Theorie des Klanges, Leipzig, 1787.

[6] R. W. ClOUGH, The finite element method in plane stress analysis, in Proceedings of the ASCE Conference on Electronic Computation, Pittsburgh, PA, 1960. 
[7] R. W. Clough, Thoughts about the origin of the finite element method, Comput. \& Structures, 79 (2001), pp. 2029-2030.

[8] R. Courant, Über die Anwendung des Dirichletschen Prinzipes auf die Probleme der konformen Abbildung, Math. Ann., 71 (1912), pp. 145-183.

[9] R. Courant, Über die Existenztheoreme der Potential- und Funktionentheorie, J. Reine Angew. Math., 144 (1914), pp. 190-211.

[10] R. Courant, Über direkte Methoden in der Variationsrechnung und über verwandte Fragen, Math. Ann., 97 (1927), pp. 711-736.

[11] R. Courant, Variational methods for the solution of problems of equilibrium and vibrations, Bull. Amer. Math. Soc., 49 (1943), pp. 1-61.

[12] L. EulER, Methodus inveniendi lineas curvas maximi minimive proprietate gaudentes sive solutio problematis isoperimetrici latissimo sensu accepti, Lausannae \& Genevae, 1744. Enestr. 65, Opera Omnia, Ser. I, Vol. 24.

[13] L. Euler, Institutionum calculi integralis, Petropolis, 1768. Enestr. 342, Opera Omnia, Ser.I, vol. 11.

[14] L. Euler, Methodus Nova et Facilis Calculum Variationum Tractandi, Noci commentarii acad. scient. Petropolitanae, 16 (1772), pp. 35-70. Enestr. 420, Opera Omnia, Ser. I, Vol. 25, pp. 208-235.

[15] B. G. Galerkin, Rods and plates. Series occurring in various questions concerning the elastic equilibrium of rods and plates, Engineers Bulletin (Vestnik Inzhenerov), 19 (1915), pp. 897908 (in Russian).

[16] C. F. GAuss, Allgemeine Lehrsätze in Beziehung auf die im verkehrten Verhältnisse des Quadrates der Entfernung wirkenden Anziehungs- und Abstossungs-Kräfte, Magnetischer Verein, 1839. Werke Vol. 5, pp. 195-242.

[17] M. Giaquinta and S. Hildebrandt, Calculus of Variations. I, Springer, Berlin, 1996.

[18] M. Giaquinta and S. Hildebrandt, Calculus of Variations. II, Springer, Berlin, 1996.

[19] M. H. Gutknecht, Numerical experiments on solving Theodorsen's integral equation for conformal maps with the fast Fourier transform and various nonlinear iterative methods, SIAM J. Sci. Statist. Comput., 4 (1983), pp. 1-30.

[20] P. Henrici, Applied and Computational Complex Analysis, Vol. 3, John Wiley, New York, 1986.

[21] D. Hilbert, Über das Dirichletsche Prinzip, Jahresbericht der Deutschen MathematikerVereinigung, 8 (1900), pp. 184-188. Reprinted in J. Reine Angew. Math., 129 (1905), pp. 63-67.

[22] D. Hilbert, Über das Dirichletsche Prinzip, Math. Ann., 59 (1904), pp. 161-186.

[23] A. Hrennikoff, Solution of problems of elasticity by the frame-work method, ASME J. Appl. Mech., 8 (1941), pp. 615-715.

[24] A. Hurwitz And R. Courant, Vorlesungen über die allgemeine Funktionentheorie und elliptische Funktionen, Julius Springer, Berlin, 1922.

[25] G. KIRchHofF, Über das Gleichgewicht und die Bewegung einer elastischen Scheibe, J. Reine Angew. Math., 44 (1850), pp. 51-92.

[26] R. KöNIG, Beitrag zur Theorie der Klangfiguren von Wheatstone, Annalen der Physik und Chemie/Poggendorfs Annalen, 122 (1864), pp. 238-245.

[27] R. KöNIG, Konforme Abbildung der Oberfläche einer räumlichen Ecke, Math. Ann., 71 (1912), pp. 184-205.

[28] G. Kron, Tensor Analysis of Networks, John Wiley, New York, 1939.

[29] G. Kron, A set of principles to interconnect the solutions of physical systems, J. Appl. Phys., 24 (1953), pp. 965-980.

[30] A. W. Leissa, The historical bases of the Rayleigh and Ritz methods, J. Sound Vibration, 287 (2005), pp. 961-978.

[31] S. Levy, Structural analysis and influence coefficients for delta wings, J. Aeronautical Sci., 20 (1953), pp. XXX-XXX.

[32] D. McHenry, A lattice analogy for the solution of plane stress problems, J. Inst. Civ. Eng., 21 (1943), pp. 59-82.

[33] J. T. Oden, Historical comments on finite elements, in A History of Scientific Computing (Princeton, NJ, 1987), ACM, New York, 1990, pp. 152-166.

[34] G. I. Petrov, Application of Galerkin's method to the problem of stability of flow of a viscous fluid, J. Appl. Math. Mech., 4 (1940), pp. 3-12 (in Russian).

[35] G. POLYA, Sur une interprétation de la méthode des différences finis qui peut fournir des bornes supérieures ou inférieures, C. R. Acad. Sci. Paris, 235 (1952), pp. 995-997.

[36] B. Riemann, Grundlagen für eine allgemeine Theorie der Functionen einer veränderlichen complexen Grösse, Inauguraldissertation Göttingen, 1851 (Gesammelte Werke, pp. 3-43). 
[37] B. Riemann, Bestimmung einer Function einer veränderlichen complexen Grösse durch Grenzund Unstetigkeitsbedingungen, J. Reine Angew. Math., 54 (1857), pp. 111-114 (Gesammelte Werke, pp. 96-100).

[38] W. RITZ, Über eine neue Methode zur Lösung gewisser Variationsprobleme der mathematischen Physik, J. Reine Angew. Math., 135 (1908), pp. 1-61.

[39] W. Ritz, Theorie der Transversalschwingungen einer quadratischen Platte mit freien Rändern, Ann. Phys., 18 (1909), pp. 737-807.

[40] K. Schellbach, Probleme der Variationsrechnung, J. Reine Angew. Math., 41 (1852), pp. 293363.

[41] J. W. Strutt (Lord Rayleigh), The Theory of Sound, Vol. I, Macmillan, London, 1894. New edition, Dover, New York, 1945.

[42] J. W. Strutt (LORD RAyleigh), On the calculation of Chladni's figures for a square plate, Philosophical Magazine Sixth Series, 22 (1911), pp. 225-229.

[43] R. L. TAYLOR, Ritz \& Galerkin: The road to the finite element method, Bull. Internat. Assoc. Comput. Mech., 12 (2002), pp. 2-5.

[44] W. Thomson (LATER Lord Kelvin), Sur une équation aux différences partielles qui se présente dans plusieurs questions de Physique mathématique, J. Math. Pures Appl., 12 (1847), pp. 493-496.

[45] S. P. Timoshenko, Sur la stabilité des systèmes élastiques, Annales des Ponts et Chaussées, 9 (1913), pp. 496-566. Traduit du russe par M. Jean Karpinski et Victor Héroufosse; originally published in Russian in Isvestija Kievskogo Politechnitscheskogo Instituta, Kiev, 1910.

[46] E. Trefftz, Ein Gegenstück zum Ritzschen Verfahren, 2. Int. Kongress für Technische Mechanik, Zürich, 1926, pp. 131-137.

[47] N. J. Turner, R. W. Clough, H. C. Martin, and L. J. Topp, Stiffness and deflection analysis of complex structures, J. Aeronautical Sci., 23 (1956), pp. 805-823.

[48] W. Voigt, Bemerkung zu dem Problem der transversalen Schwingungen rechteckiger Platten, Göttinger Nachrichten 1893, pp. 225-230.

[49] K. T. W. Weierstrass, Über das sogenannte Dirichletsche Prinzip, Werke, 2 (1895), pp. 4954. Read in the Academy Berlin, 14 July 1870.

[50] C. Wheatstone, On the figures obtained by strewing sand on vibrating surfaces, commonly called acoustic figures, Philos. Trans. Roy. Soc., 123 (1833), pp. 593-634. 